University of Rhode Island

DigitalCommons@URI

Open Access Master's Theses

1983

\title{
The Effect of a Hypocaloric Diet on the Body Weight, Body Composition and Serum HDL Levels of Male Endurance Athletes
}

Ellen Carol Alina

University of Rhode Island

Follow this and additional works at: https://digitalcommons.uri.edu/theses

\section{Recommended Citation}

Alina, Ellen Carol, "The Effect of a Hypocaloric Diet on the Body Weight, Body Composition and Serum HDL Levels of Male Endurance Athletes" (1983). Open Access Master's Theses. Paper 1030.

https://digitalcommons.uri.edu/theses/1030

This Thesis is brought to you for free and open access by DigitalCommons@URI. It has been accepted for inclusion in Open Access Master's Theses by an authorized administrator of DigitalCommons@URI. For more information, please contact digitalcommons-group@uri.edu. 
THE EFFECT OF A HYPOCALORIC DIET ON THE BODY WEIGHT, BODY COMPOSITION, AND SERUM HDL

LEVELS OF MALE ENDURANCE ATHLETES

BY

ELLEN CAROL ALINA

A THESIS SUBMITTED IN PARTIAL FULFILLMENT OF REQUIREMENTS FOR THE DEGREE OF

MASTER OF SCIENCE

IN

FOOD SCIENCE AND NUTRITION

UNIVERSITY OF RHODE ISLAND .

1983 
MASTER OF SCIENCE THESIS

OF

ELLEN CAROL ALINA

APPROVED :

Thesis Committee

Major Professor

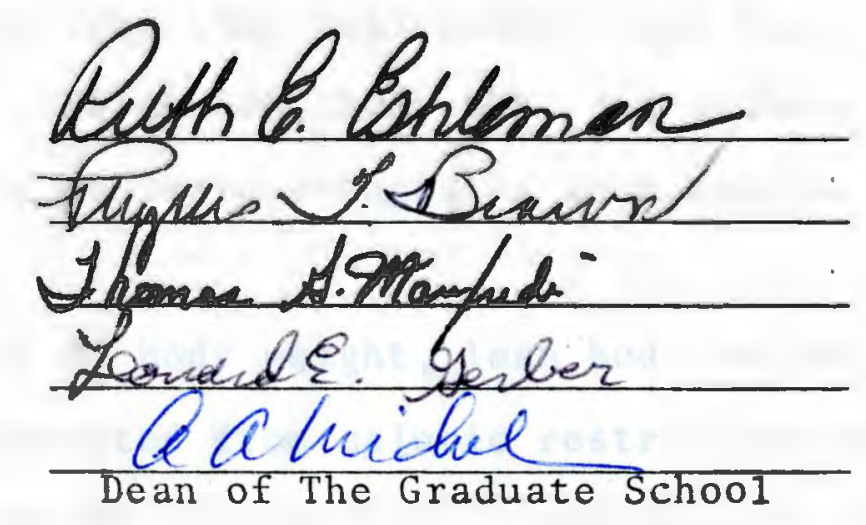

UNIVERSITY OF RHODE ISLAND

1983 


\section{ABSTRACT}

The purpose of this study was to investigate the effect of a hypocaloric diet on the serum HDL levels and body composition of endurance athletes. Sixteen male athletes, 20 - 45 years of age, volunteered to run 10 miles daily during this 18 day study. For the first 7 days of the study, the subjects consumed a baseline diet and a supplement (muffin) to maintain body weight. The experimental period included a hypocaloric diet which the runners consumed from days 8 - 18. Phlebotomy occured on days 1,8 , 10, 12, 15, and 18. The blood samples were analyzed for serum HDL, HDL-2, HDL-3, and APO A-I levels. Changes in body composition were determined prior to and after the hypocaloric period. Percent body fat was determined by skinfold thickness, and from this measurement lean body weight was calculated. Serum CPK, BUN, UUN, and urinary creatinine were used to indicate changes in lean muscle mass.

A significant loss of body weight, lean body weight, and percent body fat resulted from caloric restriction and exercise. Total HDL and HDL-2 increased significantly with weight loss and were determined to be predictive of one another. CPK levels increased and were significantly related to weight loss. BUN and UUN levels decreased and were not significantly correlated with a change in body weight or HDL. 
The findings of this study indicate that in endurance athletes, HDL levels are elevated with exercise and are further elevated if exercise is accompanied by weight loss. As a result of exercise and caloric restriction, percent body fat also decreased. Lean body weight decreased as a result of a loss of lean muscle mass and possibly other components of lean body tissue. The change in body composition of these male athletes suggests a possible mechanism for the increase in HDL levels. 


\section{ACKNOWLEDGEMENTS}

I am deeply grateful to my parents and brother Ronnie for all the love and support they have given me throughout my graduate studies. I'd first like to thank my major professor Dr. Ruthe Eshleman for many hours of advice and guidance. A thank you to Dr. Paul Thompson, Eileen Cullinane, and the $1 \mathrm{ab}$ techs at Miriam Hospital for making this project possible. Also a thank you to committee members Dr. Thomas Manfredi and Ms. Phyllis Brown for their invaluable suggestions in writing this thesis. A special thank you to committee member and friend, Dr. Leonard Gerber for always being there. I'd like to express gratitude to fellow researchers and friends Paula Ziegler and Marie Burgess for their constant mutual support and cheerfulness. Also a very special thank you to Jill Armstrong for her academic influence and warm friendship. Last but not least, a very personal thank you to Philip Ronsivalli, whose unending encouragement helped me to see the light at the end of the tunnel. 
ABSTRACT ........................

ACKNOWLEDGEMENTS .................... iv

TABLE OF CONTENTS $\ldots \ldots \ldots \ldots \ldots \ldots \ldots \ldots \ldots \ldots$

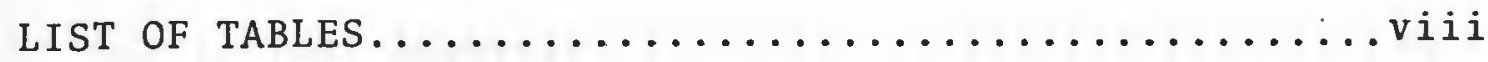

LIST OF FIGURES....................

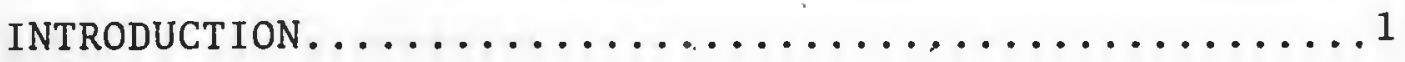

LITERATURE REVIEW..................

The Lipoproteins: Structure and

Metabolism........................

The Pathogenesis of Atherosclerosis.............10

HDL and Coronary Hear.t Disease............11

Factors Which May Influence HDL............12

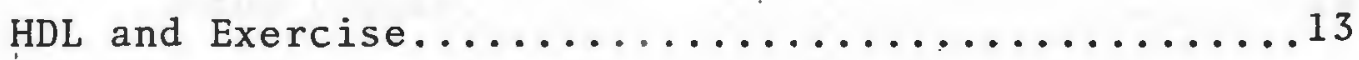

Dietary Factors as Risk Factors............17

Influence of Relative Body Weight

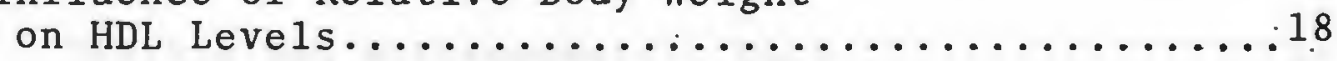

The Effect of Caloric Intake on HDL...........19

Serum Triglycerides and VLDL.............22

Body Composition.....................23

Lipoprotein Lipase..................... 27

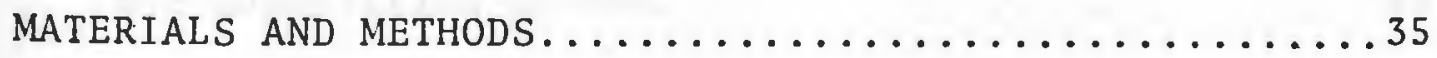

Description of Subjects.................... 35

Dietary Information.....................

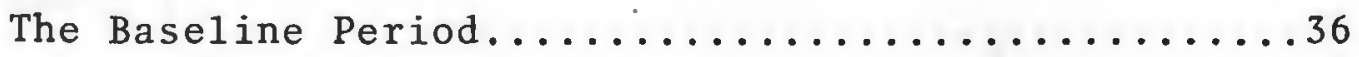


The Hypocaloric Period.................. 37

Anthropometric Determinations............. 38

Biochemical Determinations............... 38

Maximum Oxygen Uptake................42

Statistical Analysis.................. 43

Scope of Study...................... 44

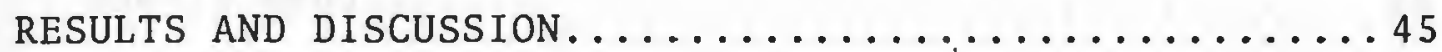

Description of Subjects................ 45

The Baseline Period (Days 1-7) ............45

Dietary Data......................... 45

Anthropometric Data.................. 45

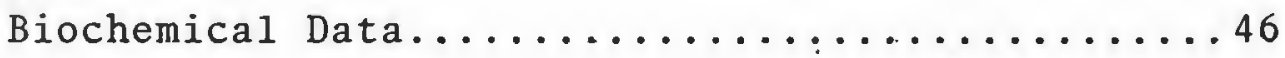

Serum Lipids...................46

Muscle Metabolites................47

The Hypocaloric Period.................. 51

Dietary and Anthropometric Data........... 51

Biochemical Data.................... 53

Serum Lipids................... 53

Muscle Metabolites.................56

The Effect of Changes in Body Weight and Composition on IIDL..................60

SUMMARY AND CONCLUSION.................. 63

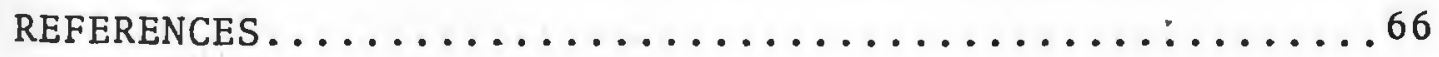
APPENDIX 1 


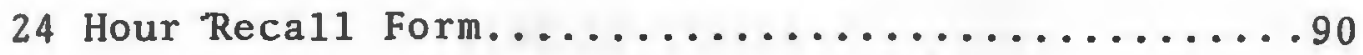
APPENDIX 2

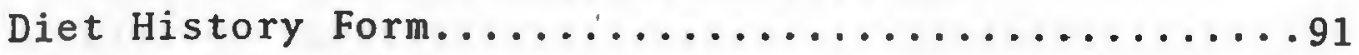
APPENDIX 3

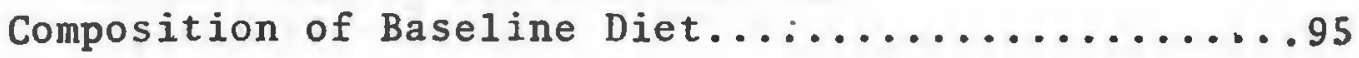
APṔENDIX 4

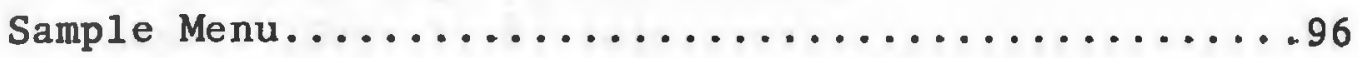
APPENDIX 5

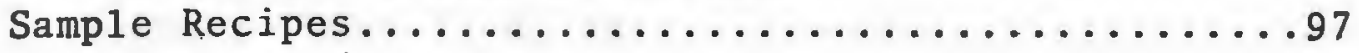
APPENDIX 6

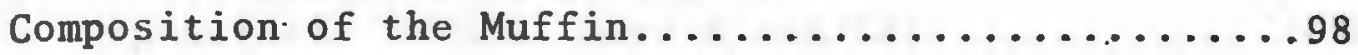
APPENDIX 7

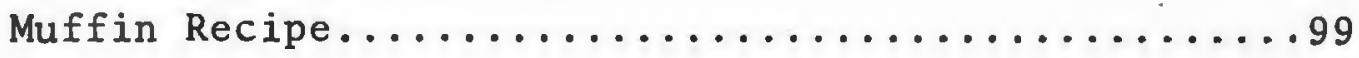
APPENDIX 8

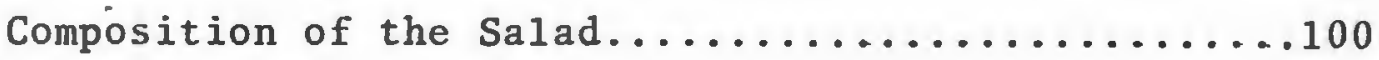
APPENDIX 9

Methods of Analyses for HDL and APO A-I..........101 BIBLIOGRAPHY ............................. 102 


\section{LIST OF TABLES}

I Initia1 Physica1 Characteristics of Sixteen Runners..................... 76

I I Mean Nutrient Intake of Sixteen Runners during the Baseline and Hypocaloric Periods.................. 77

III Mean and SD Values for Body Weight, and Percent Body Fat of Sixteen Runners (Days $1,8,18$ ).............. 78

IV Mean Serum and SD Values for HDL and APO A-I Levels of Sixteen Runners (Days $1,8,18) \ldots \ldots \ldots \ldots \ldots \ldots \ldots \ldots$

$\mathrm{V}$ Mean and SD Values for CPK and Muscle Metabolites During the Hypocaloric Period (Days 8 and 18 ) ......... 80 


\section{LIST OF FIGURES}

I Plot of Mean Change in Calories Over 18 Day Period....................... 81

II Mean Change in Weight by Day $\ldots \ldots \ldots \ldots \ldots \ldots 8$

II Mean Changes in Percent Fat by Day.........83

IV Mean Changes in Lean Body Weight by Day......84

V Plot of Mean HDL Levels by Day...........85

VI P1ot of Mean HDL-2 Levels by Day..........86

VII Plot of Mean HDL-3 Levels by Day..........87

VIII P1ot of Mean APO A-I Levels by Day..........88

IX Mean HDL and APO A-I Levels During the Hypocaloric Period................ 89 


\section{INTRODUCTION}

Coronary heart disease or atherosclerosis is one of the primary causes of death in the United States. Consequently, attempts are being made to discover not only how the disease manifests itself physiologically and biochemically, but also what factors increase or lower the risk of developing coronary heart disease.

Atherosclerosis may progress asymptomatically for many years making it difficult to trace the actual cause of the disease. Atherosclerotic lesions usually occur in the intima or the inner most layer of the artery. They may appear as one of three types: fatty streaks, fibrous plaques, or complicated lesions. Fatty streaks are commonly found in young people and are characterized by a small number of intimal smooth muscle cells containing or surrounded by 1ipid. On the other hand, fibrous plaques are characteristic of advancing atherosclerosis, are elevated and therefore protrude into the lumen of the artery. The complicated lesions appear to be fibrous plaques that have been altered as a result of hemorrhage, calcification, cell necrosis, or mural thrombosis. These lesions are usually associated with occlusive disease (1).

of current interest, is the relationship of dietary

factors to coronary heart disease. Investigators concerned with the intake of dietary fat and cholesterol and its relationship to coronary heart disease have indicated that the risk of death from coronary heart disease is inversely 
related to the intake of polyunsaturated fatty acids and directly related to the intake of cholesterol $(2,4)$.

Research in the area of lipoprotein metabolism and its relationship to coronary heart disease is expanding $(5,6)$. For example, the protective effect of high density lipoproteins (HDL) against the disease has been demonstrated by studies which have shown an inverse relationship between HDL and coronary heart disease $(6,7)$.

Factors which affect HDL levels have been explored. For example, the studies of Gordon et a1. (7) and Keys indicated that relative body weight is inversely related to HDL-cholesterol levels. It has also been demonstrated that obese patients have an average HDL-cholesterol concentration consistently lower than that of a control, non-obese population (8). Hartung et a1. (9) and Wood et al. (10) observed elevated HDL levels in a non-obese population of marathon runners. The former suggested relative body weight as a possible determinant of HDL levels, since the marathon runners and joggers weighed significantly less and had smaller tricep skinfolds than the active subjects. Exercise was also shown to be positively related to $\mathrm{HDL}$ levels $(9,10)$.

Others have observed the relationship of reduced caloric intake and HDL levels. In fact, observations that an inverse relationship exists between relative body weight and HDL-cholesterol initiated interest in caloric intake as a possible indicator of HDL levels. Weltman et a1. (11) found that HDL levels decreased significant1y in subjects 
whose caloric intake was restricted, while no change in HDL levels resulted in those whose caloric intake was restricted and who participated in mild exercise. They concluded that during weight loss, exercise has a protective effect against a decrease in HDL.

Thompson et al. (2) reported similar results. However after 8 months of weight stabilization, the HDL levels began to increase. They suggested that a latent effect occurs and that HDL levels rise once weight loss is maintained over a period of time (12).

Changes in body composition which occur during weight loss may affect HDL levels. In an exercising male population, Leon et al. (13) observed a relationship between weight loss due to fat loss, lean muscle mass gain, and increased HDL. Although caloric restriction without exercise appeared to result in both fat and lean muscle loss (14), when combined with exercise, it resulted in fat loss and a slight decrease in lean muscle mass (15). Changes in body composition such as those associated with weight loss due to caloric restriction and exercise may be determinants of HDL levels:

Although research indicates that exercise increases HDL levels in male athletes $(9,10)$, little data is available on the effect of a hypocaloric diet on the HDL levels of endurance athletes. It is necessary to ask the question, what will happen to HDL levels and body composition in endurance athletes during a hypocaloric diet? Therefore, 
this study is designed to test the following hypotheses: Ho: Serum HDL levels in endurance athletes will increase with a hypocaloric diet. Hl: Adipose tissue and lean. muscle mass of endurance athletes will decrease with a hypocaloric diet. 


\section{REVIEW OF LITERATURE}

\section{THE LIPOPROTEINS: STRUCTURE AND METABOLISM}

Until recently, researchers have investigated the inverse relationship between serum cholesterol and coronary heart disease $(5,16,17)$. Currently, emphasis is being placed on the lipoproteins. A knowledge of the structure, metabolism, and interaction of the lipoproteins, including high density lipoprotein (HDL), is important for understanding how lipoprotein levels may be related to the incidence of coronary heart disease.

Lipoproteins are classified into four major groups: chylomicrons, very low density lipoproteins (VLDL), low density lipoproteins (LDL), and high density lipoproteins (HDL). The basic structure of lipoproteins includes a protein moeity, known as the apoproteins (APO), together with polar lipids in a surface film surrounding a neutral lipid core (18). These lipoproteins vary in composition according to the percentages of cholesterol, cholesteryl esters, triglycerides, and phospholipids. They also vary in their apoprotein content, specifically apoproteins AI, AII, B, CI, CII, CIII, D, and E (19). These lipid-protein complexes transport lipids and regulate lipid synthesis and catabolism.

The major role of chylomicrons is the transportation of dietary triglycerides across the gut via the lymphatic system where triglyceride exchange with other lipoproteins 
may occur. The major apoprotein of the chylomicrons is Apo C, however they do contain some Apo A and B (20). VLDL function to provide lipid and protein exchange with other 1ipoproteins and are composed predominately of triglycerides. The major apoproteins of VLDL are CI, CII, and CIII which readily exchange between VLDL, HDL, and chylomicrons (21).

LDL are the major carriers of cholesterol in the plasma. Goldstein and Brown (16) observed that the LDL receptors in - the coronary artery take up and degrade LDL at a high rate and that this may be accompanied by a net increase in cell cholesterol content. Jackson et a1. (21) pointed out that HDL can significantly modify, in a direct way, the metabolism of LDL in the arterial cells.

HDL are the smallest of the 1ipoproteins and are composed of $50 \%$ 1ipid by weight. The composition varies with phospholipids ranging from 23 to $40 \%$ by weight, cholesteryl esters from 10 to $20 \%$, unesterified cholesterol from 1.5 to $8 \%$, triglycerides from 1.5 to $4 \%$, and protein content from 37 to over $60 \%$. To some extent, this reflects differences in the proportion of the HDL subfractions, HDL-2 and HDL-3 (22). Little is presently known as to the physiological significance of these subfractions. However, it has been determined that HDL-2 is richer in lipid, Apo C, and Apo AI than HDL-3 (23). In addition, during lipolysis, it appears that HDL-3 is an intermediate between VLDL and HDL-2 (24). Apoproteins AI and AII appear to be important in the 
structural'integrity of HDL. Apo AI is an important activator of the lecithin-acyl transferase (LCAT) reaction in which HDL accepts unesterified cholesterol from LDL (25). Thus, it has been proposed that the rate of synthesis and/or catabolism of the apoproteins may be a determinant of the circulating levels of HDL particles. It is for this reason that the apoproteins, rather than HDL-cholesterol, are often measured as a determinant of total HDL (22).

HDL is synthesized and secreted by the liver and ileum as nascent HDL. Nascent HDL differs from mature HDL in that $50 \%$ of the protein moeity is Apo E, with Apo AI, B, and C contributing the remaining $50 \%$. It also is a bilaminar structure composed of phospholipids, free cholesterol, and a small amount of non-polar lipid (22).

Mature HDL is formed by the transfer and exchange of component lipids and proteins with other lipoproteins. Lipoprotein lipase (LPL), a tissue bound hydrolase which is synthesized in the cytoplasm of extrahepatic tissue, is primarily responsible for this transfer and exchange. Heparin releases the enzyme to the capillary bed of adipose tissue, heart, lung; mammary gland, and skeletal muscle, where it enhances the hydrolysis of fatty acids from circulating triglycerides $(26,28)$. Trigiycerides are released from VLDL and chylomicrons during lipolysis. During this degradation of VLDL and chylomicrons by LPL, mature HDL or HDL-2 is formed from HDL-3. This process involves the enrichment of HDL-3 particles with cholesterol and phospho- 
lipids, thus becoming less dense and ultimately forming HDL - 2 :

The released fatty acids from the triglycerides are then taken up by adipocytes, re-esterified to triglycerides and stored in adipose tissue (28). Skeletal muscle oxidizes the free fatty acids from adipose tissue or plasma triglycerides in lipoprotein-rich capillaries for fuel. Direct utilization of plasma triglyceride-fatty acids by both of the aforementioned tissues depends on the content of active LPL in their capillary beds (27).

Observations that human 1 ymph chylomicrons contain significant quantities of APO I and AII suggest that chylomicrons may be a source of APO A for HDL maturation (22). $A P O C$ is transferred from VLDL to HDL-2. The final reassembly involves the exchange of apoproteins AI and AII between HDL-3 and HDL-2. The rate of formation of HDL-2 in circulation is dependent on the activity of LPL and the concomitant rate of removal of VLDL and chylomicrons (29).

HDL exchanges readily with VLDL and chylomicrons. Triglyceride-rich VLDL are secreted by the liver and, to some degree, by the intestine and are acted upon by LPL. This leads to progressive lipolysis, loss of triglyceride, and conversion of VLDL to LDL. Chylomicrons also are converted by LPL to small cholesterol-rich particles (30). Upon lipolysis, phospholipids, unesterified cholesterol, and triglycerides are transferred from chylomicrons and VLDL to HDL. Transfer of cholesteryl esters from HDL to VLDL 
has also been observed. HDL are the best substrate for LCAT and the most probable donor of cholesteryl ester. In addition, Apo $C$ exchanges freely between HDL and VLDL. The functional significance of this transfer relates to the catalytic action of LPL. In vitro assays have shown that Apo CII is the major activator of LPL. A different and more equal distribution of Apo $C$ occurs between HDL and VLDL among individuals with elevated HDL levels. Thus, there is considerable capacity for HDL to provide VLDL and chylomicrons with the necessary. amount of Apo C (22).

In vitro, the amount of Apo $C$ transferred from VLDL to HDL during incubation of labeled VLDL with LPL was found to be proportional to the extent of triglyceride hydrolysis. This suggests that a relationship between LPL activity and HDL levels may be a function of the efficiency of VLDL and chylomicron metabolism (22). This is further supported by the increase in HDL levels which results from an increase in the lipolysis of VLDL in certain tissues. Additionally, changes in the levels of activity of LPL in various tissues support the view that synthesis of this enzyme occurs in the cells which respond to nutritional and endocrine stimulation such as the adipocytes and muscle cells (18).

The catabolism of mature HDL occurs in the liver and more specifically, in the hepatocytes. The components of plasma HDL probably catabolize through multiple independent pathways which may have little or no effect on the number of circulation pathways (22). Kinetic'studies have demon- 
strated differences in the fractional catabolic rates of the components of HDL, namely the cholesteryl esters, Apo $A$, and C.. Cholesteryl esters are removed by HDL in circulation and direct uptake may occur in the liver, adrenal cortex, and gonads. Apo AI and AII are catabolized at similar rates within HDL. Although the sites of Apo.C catabolism are presently unknown, HDL may serve as a major vehicle for the clearance of Apo C from circulation (23).

Knowledge of the mechanism by which HDL influences the risk of coronary heart disease is increasing. 'Lipolysis of VLDL, and the subsequent transfer of lipids and apoproteins to HDL play a role in this mechanism. Further study of lipoprotein interaction may therefore offer a better understanding of coronary heart disease.

\section{THE PATHOGENESIS OF ATHEROSCLEROSIS}

The pathogenesis of the atherosclerotic lesion in coronary heart disease is still unclear, however early researchers seem to agree on the mechanism of its formation $(33,34,5)$. It is apparent that lipoproteins of many sizes, including HDL and LDL, pass through the endothelial cells of the intima. Interruption of the endothelial barrier due to mechanical injury, hypercholesterolemia, homocystinemia, or immune malfunction causes a platelet releasing response in addition to smooth muscle cell proliferation. The proliferated smooth muscle cells reach a maximum thickness and 
are surrounded by newly formed collagen, fibrils, and proteoglycans. In addition, smooth muscle cell proliferation is supported by LDL. LDL provides lipid for the cell membrane. However, when the endothelium is injured, it will promote atherosclerotic lesions (33). The role of HDL is to accept unesterified cholesterol from LDL via the enzyme LCAT (25). In this way, HDL will partially inhibit the uptake and degradation of LDL and partially suppress the net increment in cell sterol content induced by LDL, thus inhibiting or perhaps reversing the atherosclerotic lesion (34).

\section{HDL AND CORONARY HEART DISEASE}

As early as 1951, Barr et a1. (35) demonstrated that subjects with coronary heart disease had higher cholesterol levels than the controls. Later, Kannel et al. (36) confirmed that the most significant lipid aberration was low HDL cholesterol levels. They further confirmed the work of Goffman et al., 1966 which indicated the possibility that the risk of coronary heart disease was inversely related to HDL.

Recently, studies have shown an inverse relationship between HDL levels and coronary heart disease $(5,7)$. In one study (5), the cholesterol pool size of eight patients with hypercholesterolemia was determined. Pool size was found to be unrelated to the mean coricentration of total 
cholesterol, total triglyceride, VLDL and LDL. However, a strong negative correlation existed between pool size and. HDL leve1s. The mean HDL-cholesterol level in subjects with ischemic heart disease was $30 \mathrm{mg} / \mathrm{dl}$ as compared to 55 $\mathrm{mg} / \mathrm{d} 1$ in controls (5).

Over a 20-year period, the Framingham study attempted to correlate risk factors with heart disease. In 1968, the blood samples of 2,815 disease-free men and women, 49 to 82 years of age, were analyzed for lipids and lipoproteins. Four years later, the same analyses were performed. 'During this time, $8 \%$ of the men and $5 \%$ of the women had developed coronary heart disease. The incidence rate of coronary heart disease in individuals with HDL-cholesterol leve1s below $35 \mathrm{mg} / \mathrm{dl}$ was 8 times that in those with HDL levels $65 \mathrm{mg} / \mathrm{d} 1$ or above (7).

A 38-year longitudinal study also instigated queries as to possible HDL determinants. The subjects in this study were 284 business and professional men, 44 to 55 years of age. Five years after the intial blood sampling, $19 \%$ of the subjects had died from coronary heart disease and 288 from other causes. Of those who died of coronary heart disease, the mean HDL-cholesterol levels at death and at entry were lower by $4.42 \mathrm{mg} / \mathrm{d} 1$ and $3.30 \mathrm{mg} / \mathrm{dl}$, respectively than those of the individuals who died from other causes (6). FACTORS WHICH MAY INFLUENCE HDL 
The inverse relationship of HDL and coronary heart diseáse has been clearly demonstrated $(5,6,7)$. This causal relationship warranted an attempt to determine the endogenous and exogenous factors which may effect HDL levels. It has been known that women have higher HDL values than men and that estrogens increase HDL in both men and women. (19). For example, the Framingham study stated that HDLcholesterol levels in women were significantly higher than those of men by a factor of $10 \mathrm{mg} / \mathrm{dl}$ (7).

\section{HDL AND EXERCISE}

Exercise is another factor which has been shown to increase $\mathrm{HDL}(9,10,37)$. This has been demonstrated in trained endurance athletes, as well as in sedentary men after training. Wood et a1. (10) observed that the mean HDL-cholesterol 'level of 41 runners who ran an average of $39 \mathrm{miles} /$ week was $34 \%$ higher than that of the control groups. Hartung et al. (9) observed 59 marathon runners and 85 joggers who had $34 \%$ and $26 \%$ higher HDL levels, respectively than 74 sedentary subjects. During the 12 months prior to the study, all the marathon runners completed a 26.2 mile marathon and continued to run an average of 11 miles/week. The number of miles run was shown to be the best predictor of both HDL cholesterol and the ratio of HDL to total cholesterol.

Criticisms of these conclusions are related to the 
possibility of other, unmeasured variables affecting HDLcholesterol levels. Young and Barboriak (38) concluded that the 3 groups probably differed in other ways, such as in overall behavior patterns. They also suggested that conclusions based on dietary data may be inaccurate due to inadequate data. In addition, Williams et al. (39) suggested that individuals with initially higher HDL-cholesterol levels have a greater tendency to take up running as a sport. For example, during a 1-year training program of initially sedentary men, they observed that the subjects who ran the most had initially higher baseline HDL-cholesterol levels than the low mileage runners. Baseline HDL-cholesterol remained a significant predictor of miles run when intervening variables were accounted for (percent body fat maximum $\mathrm{O}_{2}$ uptake, alcohol intake and smoking). Therefore, it was concluded that an association exists between the tendency to participate in regular vigorous exercise and HDL-cholesterol.

Wetzler (40) further commented that the HDL-cholesterol levels of marathon runners with high initial HDL levels were not significantly different from joggers with high HDL levels in the Hartung study (9). He suggested that this may be due to hereditary factors, or to the possibility that HDL may level off or increase very slowly, at a particular level of running., "

The level of intensity, as well as the type of, and amount of exercise are thought to be related to an increase 
in HDL levels $(41,39)$. In a population of 23 active men, a positive correlation existed between the amount of weekly exercise in kilometers and the plasma HDL-cholesterol concentration. These men who trained for 5 years had. HDL 'levels of $68.5 \mathrm{mg} / \mathrm{dl}$, while the sedentary men had levels which ranged from 59.8 to $44.2 \mathrm{mg} / \mathrm{dl}$. The prolonged effect of training may have influenced the HDL levels (41). In 81 sedentary men, observations that increase in the number of miles run/week was accompanied by an increase in plasma HDLcholesterol supported this hypothesis. However, HDL-cholesterol did not begin to change with mileage before the completion of 9 months of training. Therefore, there was a stronger correlation between miles run and HDL-cholesterol at one year than at 9 months (39).

In another study, 293 healthy 18 to 30 year old males who received different intensities of training (endurance training, mixed training, power training, and no training) were evaluated for serum lipids. The mean HDL-cholesterol levels of the athletes in endurance training was $29 \%$ higher than those in power training and $8 \%$ higher than those in mixed training (42). Masarei et al. (43) observed a similar effect in a population of 43 male business executives who were designated as having high endurance fitness levels or low endurance fitness levels. The subjects with high levels of endurance fitness had $2 \%$ higher HDL-cholesterol levels than those with low endurance fitness levels. These studies indicate that the levels of intensity of training have an 
effect on HDL-cholesterol levels.

Aerobic sports other than running a1so, affect HDL-cholesterol leve1s. The HDL-cholesterol levels of a population of middle-aged male tennis players, wher adjusted for age, weight, cigarette smoking, and alcohol intake, were 8.7 $\mathrm{mg} / \mathrm{dl}$ higher than those of the sedentary men (44). Similar results were observed in 34 female swimmers, grouped by exercise-intensity as competitive swimmers, synchronized swimmers, and controls. HDL-'cholesterol was $17 \%$ and $22 \%$ higher for competitive swimmers than for synchronized swimmers and controls respectively (45).

Other studies have reported an increase in HDL with exercise in sedentary men, as well as in trained men (39, $\left.46^{\circ}, 47\right)$. After 2 months of mild exercise, 110 sedentary men, 40 to 50 years of age, increased their exercise intensity to a moderate level for 2 months. HDL-cholesterol increased with exercise intensity; first, by $6 \%$; then, by a total of $10 \%$ at the end of the protocol (46). In another study, the HDL-cholesterol levels of 100 sedentary men increased by $7 \%$ during a 12 -week training program of increasing intensity (47).

In addition to the effect of training on HDL-cholesterol in healthy men, it was also shown to increase with exercise in a group of 18 male patients with coronary heart disease. Aerobic exercise training was conducted 3 times a week for 20 minutes and increased in intensity for a 3 -month period. HDL-cholesterol increased by $5 \%$ during the training period 
$(48) \cdot$

HDL levels also may be influenced by cigarette smoking, sex differences, and alcohol consumption $(3,49,50)$. It appears that HDL levels tend to be highest in a population of nonsmoking, moderate alcohol consuming, male endurance athletes.

\section{$\underline{\text { DIETARY FACTORS }} \underline{\text { AS }}$ RISK $\underline{\text { FACTORS }}$}

The relationship of dietary factors as risk factors to coronary heart disease is of current interest. Until recently, research concerned with the relationship of diet to coronary heart disease concentrated on the intake of dietary fat and cholesterol $(51,2)$. Shekelle et al. (2) demonstrated that the risk of death from coronary heart disease was inversely related to the intake of polyunsaturated fatty acids and positively related to the intake of dietary cholesterol. This was observed in a group of 23 men (40 to 49 years of age) at high risk for coronary heart disease. These subjects were required to reduce their saturated fat intake and to partially substitute it with polyunsaturated fats. After 4 years on this dietary regimen, their HDL-choesterol was $20 \%$ higher than that of the control group. The correlation between HDL-cholesterol and the P:S ratio of the diet was highly significant. When adjusted for other variables, particularly body weight, the correlation between HDLcholesterol and P:S ratio was reduced (51). This may indi- 
cate that a decrease in body weight is partially responsible for the increase in HDL-cholesterol levels.

\section{INFLUENCE OF RELATIVE BODY WEIGHT ON HDL LEVELS}

Interest in the relationship between relative body weight (actual weight divided by the ideal weight according to the Metropolitan Life Insurance tables) and HDL was initiated by studies which indicated that for inactive subjects, relative weight had the highest inverse correlation $(\mathrm{p}<$ $0.001)$ with HDL levels of all the risk factors. Additiona1ly, triglyceride levels were reported to have a significantly low negative correlation with glucose intolerance (7). This suggested that a person who was obese, had a glucose intolerance, or higher triglyceride levels than normal, was more likely to have a low HDL level. In fact, Keys (6) showed relative body weight to be the only significantly correlated risk factor with HDL-cholesterol. This relationship was also seen in physically active men. Analysis of covariance indicated that male marathon runners and joggers had significantly lower body weights and higher HDL levels than.. sedentary controls (9).

Another study investigated the relationship between body weight and HDL-cholesterol levels in a random cluster of 742 individuals ranging in age from newborns to 70 years of age. The HDL-cholesterol levels of both the males and females were inversely correlated with body weight, other 
measures of adiposity, and plasma triglyceride. levels (52). The possible role of relative weight as a factor in the regulation of $H D L$ has been noted in the significantly low HDL-2 levels in obese subjects (53).

\section{THE EFFECT OF CALORIC INTAKE ON $\underline{\text { HDL }}$}

The inverse relationship of relative body weight and HDL-cholesterol has initiated interest in caloric intake as a possible indicator of HDL levels.' Presently, little is known of the relationship between reduced caloric intake and HDL levels. One of the first groups to explore this was Mann et al. in 1955. Four men participated in a 10week program which consisted of 4 periods. The study determined changes in body weight and body fat after a control diet, a hypercaloric diet and exercise, a hypercaloric diet without exercise, and a hypocaloric diet with exercise. In all 4 periods, fat comprised 50 to $51 \%$ of the diet. During the hypocaloric period, the loss of body weight, as well as fat was significant. However, HDL levels did not change significantly. Although calories were reduced later on in the study, the high fat content of the diet may have contributed to this lack of change (54).

In a later study (55), HDL levels were increased by $68 \%$ in a group of hyperlipidemic men who lost $12 \%$ of their initial body weight. However, individual responses were highly variable. Although the weight reducing diet and 
control diet had a similar caloric distribution, the cholesterol content of the reducing diet was low (200 to 300 $\mathrm{mg} / \mathrm{day})$ and the P:S ratio, high (2.0 to 3.0$)$.

In another study (56), this effect was demonstrated in a population of 301 men judged to be at high risk of coronary heart disease. A special intervention program was incorporated which included counselling to eliminate cigarette smoking and to reduce dietary cholesterol and total fat intake for weight reduction. A $6 \%$ increase in HDL-cholesterol was noted in the intervention group. Among this group, the increase in.HDL-cholesterol was greatest in those who were adhering well to the diet and lost body weight (56).

Similarly, HDL-cholesterol has been shown to increase during weight loss of obese subjects. Thirty obese male and female subjects, 35 to 65 years of age, whose obesity was of genetic or nutritional origin received a hypocaloric hypocholesterolmeic diet. Following this hypocaloric diet and 40 to 50 days of weight stabilization, a significant decrease of total triglycerides, total cholesterol, VLDL, and LDL-cholesterol, and a significant increase of HDL-cholesterol and Apo A-I were observed (57). Seven severely obese males and females with a mean age of 37.4 years lost $21.7 \mathrm{~kg}$ of weight on a 600 to $900 \mathrm{kcal}$ diet. Before weight reduction, their mean HDL-cholesterol levels were below normal. However, after 15 months of weight stabilization, HDL-cholesterol increased by $19 \mathrm{mg} / \mathrm{d} 1(\mathrm{p}<0.02)$. Thus, in obesity, HDL- 
chol sterol levels are reversible to some extent by stabilized weight loss (8).

- Mancini et a1. (58) observed changes in plasma 1ipoproteins when 6 obese females lost $15 \mathrm{~kg}$ during a 6-week fast. HDL decreased slightly (.05\%). If the study had been longer and the weight loss had been stabilized, HDL levels may have increased as demonstrated by Contaldo et al. (8) .

Changes in HDL levels have been observed to accompany weight loss achieved either by exercise or by a combination of diet and exercise $(59,15)$. Ten obese men, 19 to 31 years of age, walked on a treadmill for 15 to 30 minutes a day for 16 weeks. Although their caloric intake was not regulated, a decrease in caloric intake was evident from weeks 4 to 12 . A mean weight 1 oss of $5.7 \mathrm{~kg}$ resulted in a $15.5 \%$ increase in HDL-cholesterol (13).

In other studies of populations who exercised and whose caloric intake was restricted, HDL levels have not increased immediately $(11,12)$. Weltman et a1. (11) observed the effect of a 10 -week exercise and/or $500 \mathrm{kcal} / \mathrm{day}$ diet regimen on weight and lipid levels of 58 sedentary males with a mean age of 47 years. Caloric restriction resulted in a weight 1 oss of $5.45 \mathrm{~kg}$; caloric restriction plus exercise, $5.95 \mathrm{~kg}$; and exercise alone, $0.91 \mathrm{~kg}$. Although HDL levels decreased significantly when calories were restricted, they did not change when exercise accompanied caloric restriction nor when exercise did.not accompany caloric 
restriction. They suggested that during weight loss, exercise alone has a protective effect against a decrease in HDL. Thompson et a1. (12), reported similar results among 15 women on a 10-week exercise and hypocaloric regimen. After 10 weeks, energy expenditure rose from 54 to $133 \mathrm{kcal} /$ day. The mean weight decreased $9.7 \mathrm{~kg}$ and HDL-cholesterol, by $5.0 \mathrm{mg} / \mathrm{dl}$. However, during the 8 -month period of weight stabilization, HDL levels increased $3.0 \mathrm{mg} / \mathrm{dl}$. The researchers suggested that there is a latent effect whereby HDL levels increase once the weight is maintained over a period of time.

\section{SERUM TRIGLYCERIDES AND VLDL}

A significant negative relationship exists between concentration of VLDL and HDL. Therefore, when HDL increases, a subsequent decrease occurs in VLDL levels. VLDL and serum triglyceride levels are higher in the obese than in the non-obese individual. In the normolipidemic non-obese individual, 'low fasting triglyceride levels are a reflection of current dietary intake. In the fasting obese individual, however, triglycerides continue to be elevated above the norm $(60)$. This deviation of triglyceride levels in the obese, the apparent increase in HDL during the 1ipolysis of triglyceride-rich lipoproteins, and, the inverse relationship between HDL levels and triglyceride levels, initiated interest in lipoprotein kinetics as an approach 
to explaining HDL determinants. During the lipolysis of triglyceride-rich particles (VLDL) at the endothelial surface of extra-hepatic tissues, triglycerides are transferred from VLDL to HDL (22). In an attempt to deterinine the mechanism by which HDL increase during weight loss, investigators have looked at the effect of weight loss on VLDL and serum triglycerides.

0lefsky et a1. (61) reported that plasma triglycerides decreased significant1y $(p<0.0001)$. when 36 obese subjects lost a mean of $10.9 \mathrm{~kg}$ on a 600 to $1600 \mathrm{kcal} / \mathrm{day}$ hypocaloric diet. A greater reduction in plasma triglycerides was observed in those subjects who had higher plasma triglyceride levels prior to weight reduction. In addition, VLDL-triglyceride production rates decreased. These data indicate that although the weight loss in the most obese; and least obese subjects was similar, percent fat loss and the reduction in plasma triglyceride levels was greater in the most obese subjects. This decrease in VLDL and triglyceride levels with weight loss may support the proposed theory of the elevation of HDL with weight loss for obese subjects.

\section{BODY COMPOSITION}

The loss of weight as a result of caloric restriction and/or exercise will result in altered body composition. This effect has been demonstrated in athletes, as well as in lean and obese subjects $(62,63)$. Athletes represent a 
unique population with regard to body composition. In particular, runners tend to have a much lower percentage of body fat than other athletes or sedentary individuals. For example, when the body composition of a group of collegeaged cross country runners was compared to that of men participating in 5 other sports, the runners had the second lowest percentage of body fat (10.3\%) (64). According to Oscai (65), the bodies of sedentary college professors contained approximately twice as much fat (16.3\%) as those of marathon runners $(7.5 \%)$ of the same age. Mayhew et al. (66), added that physically active men have a higher percentage of lean body mass than sedentary men.

Training often results in minimal weight loss or even an increase in body weight with a simultaneous significant decline in body fat (48). For example, during a season of varsity competition, the body weight of college basketball and hockey players remained constant while the subcutaneous fat of the chest, abdomen, and triceps decreased (65). A similar effect was observed in 23 sedentary, lean, healthy, male college students who underwent 9 weeks of physical conditioning for 5 hours/week. While the lean body mass of these subjects increased by $14 \mathrm{~kg}$, the mean weight decreased $1 \mathrm{~kg}$, and percent fat, $3 \%(66)$. In another study in which 55 relatively sedentary male students participated in a 10 week jogging program, body weight decreased by $1.01 \mathrm{~kg}$, percent fat by $1.11 \%$, while lean body weight remained essentially the same (.62). These studies indicated that the intensity 
of physical exercise may result in changes in body composition. These changes were also evidenced in a group of trained and untrained individuals who had the same average weight and height. The physically active group had a higher proportion of lean body mass than those who were less accustomed to physicai activity (67).

Similarly, changes in body composition were demonstrated in 8 obese individuals ( $25 \%$ fat weight) who ran and walked 60 minutes a day, 5 days a week for 9 weeks. The exercise resulted in a mean weight $10 s \mathrm{~s}$ of $3.2 \mathrm{~kg}$, a fat loss of $3.9 \%$, and an increase in lean body mass of $2.7 \mathrm{~kg}$ (66). Lewis et a1. (15) reported significant reductions in percent fat $(4.9 \%)$, total body weight $(4.2 \mathrm{~kg})$, and a slight increase in lean muscle mass $(1.1 \mathrm{~kg})$ in 32 obese women during a 17-week exercise program. Although the result of exercise on lean body mass is controversial, the aforementioned studies indicate that prolonged exercise may result in weight loss, fat loss, and an increase in lean muscle mass in the athlete, in the lean, or in the obese individual.

Others have investigated the effect of caloric restriction on body composition. Oscai (65) demonstrated the loss of large amounts of lean tissue, in addition to fat, when the weight of an obese individual was reduced by mean's of caloric restriction. Estimates of the contribution of the lean component of the tissue lost to the total weight loss were variable but amounted to as much as 35 to $45 \%$. Weltman et al. (11) observed similar effects in 58 sedentary 
men whose caloric intake was restricted for 10 weeks. They lost $5.95 \mathrm{~kg}$ of weight, $2.5 \%$ body fat, and $1.92 \mathrm{~kg}$ of 1 ean body weight. On the other hand, Buskirk et al. (14) reported a substantial loss of body fat, and little change in lean muscle mass, with weight loss in obese subjects after caloric restriction (600 to $1600 \mathrm{kcal} / \mathrm{day})$.

Similar changes in the body. composition of lean and obese subjects during caloric restriction have been reported $(63,68)$. In an 11 -week study, 32 non-obese male subjects given a diet of approximately $1570 \mathrm{kcal} / \mathrm{day}$ experienced a weight loss of $16.8 \mathrm{~kg}, 40 \%$ of which was adipose tissue; $12 \%$ lean body mass; and $48 \%$, water (62): A similar effect was observed in obese subjects fed a $1200 \mathrm{kcal}$ diet for 5 days. This resulted in a mean weight loss of $0.45 \mathrm{~kg} / \mathrm{day}$ which consisted of $66 \%$ water, $35 \%$ adipose tissue, and $9 \%$ lean body mass (68). Although the absolute amount of weight loss was twice as much in the obese as in the non-obese, the percentage of the body composition lost was similar.

Investigators have reported a decrease in body weight and in body fat with exercise or caloric restriction (62, 14, 15). However, data on the effect of caloric restriction on lean muscle mass is variable. Further studies such as that of Buskirk et al. (14) demonstrated the effect of caloric restriction and exercise on body composition. Body weight and body fat decreased while lean body mass increased in some individuals and decreased in others. Weltman et al. 
(11) also combined caloric restriction with mild exercise in a population of 58 sedentary men. A mean weight loss of $5.42 \mathrm{~kg}$ resulted in a $3.6 \%$ loss of fat, and $1.15 \mathrm{~kg}$ of $1 \mathrm{ean}$ body weight. The opposite effect was observed in a population of 10 obese, college-aged men who, after 16 weeks of training, lost $5.7 \mathrm{~kg}$ of body weight, $5 \%$ body fat but gained $0.2 \mathrm{~kg}$. of lean body weight (13).

\section{LIPOPROTEIN LIPASE}

The effect of weight loss on body composition may prove to be an important determinant of HDL levels. According to several studies, the activity of lipoprotein lipase (LPL) which resides in adipose tissue and skeletal muscle increases with weight loss $(69,70)$. An increase in the activity of this enzyme may be associated with an increase in HDL (32). HDL- 2 and the ratio of HDL-2 to HDL-3 have been shown to be positively correlated with LPL activity in adipose tissue, as well as in muscle (29). The changes in body composition which enhance stimulation of LPL activity may ultimately be effective in increasing HDL levels.

Significant differences in serum lipids, lipoproteins, and LPL activity have been noted in males and fumales. In one study, 21 male and 20 female, non-obese, healthy subjects, 20 to 50 years of age, were compared for LPL activity in adipose tissue and skeletal muscle. The females had higher total LPL activities than the males. The ratio of adipose 
tissue LPL activity/skeletal'muscle LPL activity expressed per gram of tissue weight was 2.8 in males and 8.0 in females. Thirty-five percent of the LPL-activity in males, as opposed to $15 \%$ in females, was in skeletal muscle. Also, in males a positive correlation existed between the LPL activity of adipose tissue and that of the skeletal muscle ( $r=0.61$, $\mathrm{p}<0.001)$. Although HDL concentration was positively correlated with adipose tissue LPL activity in males and females $(r=0.66, p<0.001)$, it was not correlated with muscle LPL activity.

A borderline inverse correlation exists between plasma triglyceride and VLDL concentration with LPL activity in adipose tissue (males: $r=-0.41$, females: $r=-0.42$, $p<0.05)$. In females, the capacity for removal of excess plasma triglycerides is located mainly in the adipose tissue, while in males, it is located in the muscle. It has been documented that females have a higher LPL activity per gram of adipose tissue, as well as a larger average body fat mass than men (32). Also, adipose tissue LPL activity was demonstrated to be higher than skeletal muscle LPL activity (27). This may explain the elevated HDL levels in females, the noted higher total LPL activity in females, and the positive correlation between HDL concentration and adipose tissue LPL in females (71).

Skeletal muscle and adipose tissue LPL, as well as adipose tissue LPL and HDL concentration, were shown to be positively correlated in males. The LPL in muscle may be 
important for males in terms of triglyceride assimilation. The possibility of body composition and subsequent LPL activity being predictors of HDL levels warrants further investigation.

Body composition as a possible determinant of HDL levels may be further explained by examining the activity of LPL in skeletal muscle and adipose tissue, as well as the kinetics of lipolysis in vitro. In one study, 11 of 22 healthy men had high levels of HDL (1.77 mmol/1), while the other 11 had low levels (1.09 mmol/1). Triglyceride concentrations were inversely correlated with LPL activity and with the removal rate of exogenous fat load. However, although HDL-cholesterol was negatively correlated with triglyceride concentration $(r=-0.65, p<0.05)$, it was positively correlated with the removal rate of exogenous fat load $(r=0.59, p<0.01)$. These findings are compatible with the formation of HDL through catabolism of triglyceriderich 1 ipoproteins by LPL (72).

Serum lipids; as we 11 as LPL, were determined in 16 healthy sedentary male and female subjects, 32 to 65 years of age. A strong correlation was observed between LPL and HDL $(r=0.78, p<0.001)$ and a negative correlation between triglyceride concentration and HDL. These researchers concluded that the majority of HDL found in vivo originates from the LPL action (73).

Elevated levels of HDL, as well as low levels of adipose tissue and a high proportion of skeletal muscle have 
been noted in endurance athletes (64). Interest in the effects of exercise on HDL initiated investigation of the relationship between LPL levels, body composition, HDL, and exercise.

In most individuals, adipose tissue is the main assimilation site for serum triglycerides. However, in we11 trained subjects, it may be the muscle (73). This was illustrated in 26 male and female runners who ran 100 to 130 $\mathrm{km} /$ week, sprinters who ran 20 to $35 \mathrm{~km} /$ week, and controls. The male runners had slightly lower triglyceride levels $(0.89 \mathrm{mM}$ vs. $1.00 \mathrm{mM})$ and had slight1y higher HDL-cholester01 levels ( $66 \mathrm{vs} .47 \mathrm{mg} / \mathrm{d} 1$ respective $1 \mathrm{y}$ ) than the controls. The sprinters had 2.7 times higher LPL activity than the controls while the distance runners had twice as much whole body LPL as the controls $(30 \%$ in muscle and $70 \%$ in adipose tissue).

Among the runners, there was a significant correlation between kilometers run weekly and adipose tissue LPL activity $(r=0.55, p<0.05)$; between HDL-cholesterol and adipose tissue LPL activity $(r=0.62, \mathrm{p}<0.001)$; and a significant negative correlation between serum VLDL-triglycerides and muscle LPL activity $(\mathrm{r}=-0.40, \mathrm{p}<0.05)$ (32). Krauss et a1: (74) also observed this effect in 12 male runners and 20 sedentary men with a mean age of 47 years. Runners had higher LPL activity, higher levels of HDL-2a and HDL-2b, and lower levels of VLDL than the controls. Adipose tissue LPL correlated positively with total. HDL $(r=.51$, 
$\mathrm{p}<0.01)$. It was concluded that in these runners the higher LPL levels contributed to higher HDL and lower VLDL levels. Similar effects were seen in 20 middle-aged men. undergoing 15 weeks of physicai aerobic training. Serum HDL-cholesterol increased 7\%; HDL/total cholesterol $11 \%$, and adipose tissue LPL, 56\%. In spite of increased exercise, body 'weight did not change. However, according to food frequency questionnaires, caloric consumption increased by $10 \%$. The authors suggested that the changes in LPL and HDL may be attributed to unmeasured changes in diet or redistribution of body composition (75).

The adaption to exercise in endurance training increases the potential of the body to mobilize and oxidize fatty acids (32). This adaption process also influences serum lipids, lipoproteins, and LPL. The differences in the adaption to exercise in physically active and sedentary individuals may be attributed to muscular work or to the amount of body fat (32). During exercise, the uptake of. triglyceride-fatty acids by skeletal muscle is accompanied by an increase in LPL activity (76). Additionally, the low levels of adiposity in the athlete may influence the elevation of LPL. Further investigation is needed to determine the optimum body composition for increased LPL activity and subsequently increased HDL levels.

Relatively few studies have investigated the relationship between body composition and LPL activity, together with subsequent HDL levels in non-obese subjects. However, 
this relationship has been studied in obese individuals. Persson (71) looked at LPL activity in relation to body fat in 337 males and females. LPL was found to be negatively correlated with the body weight index or relative body weight in obese males $(r=-0.401, p<0.001)$. Increasing obesity was associated with decreasing LPL activity. This correlation was less evident in females. Again, this distinction between males and females may be attributed to the greater percentage of fat mass in females.

Another study demonstrated a similar effect in a population of physically fit, free living men with a mean age of 21 who were within $10 \%$ of ideal body weight. A significant negative correlation between LPL and body fat was evident $(r=0.46, p<0.05)(77)$.

Other investigators have looked at LPL activity in reference to circulating triglycerides (26). Triglyceride levels have been found to be more elevated in the obese than in the non-obese individual (53). Huttunen et al. (26) depicted a highly significant correlation between post heparin LPL and the concentration of plasma triglycerides $(\mathrm{r}=-0.053, \mathrm{p}<0.001)$ in 47 normal males. Additionally, a significant positive correlation was found between LPL activity and the fractional turnover of triglycerides in males and females: In males, relative body weight correlated significantly with serum triglyceride concentration $(\mathrm{r}=0.41, \mathrm{p}<0.01)$. It may be concluded that the relatively high levels of triglycerides seen in the obese are 
associated with low levels of LPL activity.

Evidence of lowered HDL levels and LPL activity and increased VLDL and triglyceride concentration in the obese, sedentary individual has warranted further investigation of the determinants of HDL leveis. Changes in lipids, 1ipoproteins, and LPL have been observed during weight loss: In one study, 9 grossly obese subjects fasted for a period of 10 to 13 days. During the first 8 days of the study, LPL activity decreased from $5.62 \mu \mathrm{Eq} \mathrm{FFA} / \mathrm{g} / 45$ minutes to $3.23 \mu \mathrm{Eq} F F / g / 45$ minutes. During the following 5 days however, LPL activity returned to $4.82 \mu \mathrm{Eq} \mathrm{FFA} / \mathrm{g} / 45$. minutes. This may reflect the delayed increase in HDL with caloric restriction seen in the studies by Thompson et al. (12) and Contaldo et al. (8).

Similarly, Taskinen et al. (70) calorically restricted 8 healthy, female subjects with a mean age of 31 years. Their relative body weight was $116 \%$. Initially, all subjects were fed an isocaloric diet of $45 \%$ carbohydrate, $35 \%$ fat, and $20 \%$ protein, for 2 days. Thereafter, for 7 days the subjects were put on a $400 \mathrm{kcal} / \mathrm{day}$ diet, which had a similar caloric distribution. During the study, $3.30 \mathrm{~kg}$ of body weight was lost and fat cell size diminished by $6 \%$. After 7 days, adipose tissue LPL activity decreased to $22 \%$ and skeletal muscle LPL activity decreased. HDL-cholesterol decreased $18 \%$ and serum triglycerides and VLDL were not significantly increased during caloric restriction. This study contradicted the results of other studies 
$(8,12)$. A reversal in HDL leve1s and LPL activity may have occurred with an extended experimental period and weight stabilization as in the studies by Thompson et al. (12) and Contaldo et a1. (8). Researchers have proposed that LPL activity may increase- in an attempt by the body to maintain adipose stores (28). Other data support these findings that a loss of weight, increase in LPL activity, increase in HDL, and decrease in VLDL occur. with a hypocaloric diet $(69,28)$.

Changes in body composition, as seen during weight loss with a hypocaloric diet or with exercise, may be a predictor of HDL levels (12). Studies have demonstrated LPL activity to be an indicator of HDL levelș, as well as VLDL and triglyceride concentrations $(37,72)$. The possibility that changes in body composition, particularly adipose tissue and skeletal muscle, may influence LPL activity and ultimately HDL has not been studied. Further investigation is thus needed to determine the changes that will occur in the body composition of endurance athletes with a hypocaloric diet. Increased knowledge of these possible determinants of HDL levels will help to answer questions concerning the pathology of coronary heart disease. 


\section{DESCRIPTION OF SUBJECTS}

Sixteen male endurance athletes aged 20 to 45 years, participated in this study. The athletes were recruited from local track clubs and a YMCA, as well as through newspaper advertisements. To be eligible for participation, the volunteers had to weigh between 115 to 180 lbs. with no increase or decrease in weight for 2 weeks prior to the study period. All volunteers had to run at" least 50 miles per week during the year preceding the study. Two weeks prior to and during the study, the subjects had to agree to run 10 miles/day, to abstain from racing, and to abstain from alcohol and marijuana. These variables were controlled so that effects of diet on serum lipids could be assessed. The volunteers received a stipend for participation which was reduced for those who did not complete the study.

Volunteers were excluded from participating in the study for the following reasons: persons under medical care for illnesses other than orthopedic problems; those who consumed $24 \mathrm{oz}$. of beer or $8 \mathrm{oz}$. of wine per day or who used tobacco. This was done in order to avoid the documented influences of alcohol and tobacco on HDL levels (49). Those men with LDL-cholesterol values of less than 82 or greater. than $172 \mathrm{mg} / \mathrm{dl}$ or with triglyceride levels of less than 47 or greater than $234 \mathrm{mg} / \mathrm{dl}$ were not eligible to participate in the study since it has been noted that absolute changes 
in lipid concentration may be small or exaggerated in hypoor hyper-lipidemic subjects, respectively. Another reason for exclusion was hematocrit levels of less than $40 \%$ because of the risk of anemia from repeated phlebotomy. Also, persons with uric acid values greater than $9 \mathrm{mg} / \mathrm{dl}$ were excluded because of the risk of developing symptoms of gout during the study.

\section{DIETARY INFORMATION}

Twenty-four hour recalls, food frequency information, and diet histories were obtained one week prior to the study. (Appendices 1 and 2) These instruments were used to determine the ability of the subjects to comply to the baseline diet.

\section{BASELINE PERIOD}

The composition of the baseline diet, which was determined during a previous study.(79), consisted of the following: carbohydrate, $339.9 \mathrm{gm}$; protein, $93.2 \mathrm{gm}$; fat, $85.2 \mathrm{gm}$; calories, $2443 \mathrm{kcal}$; cholesterol, $389 \mathrm{mg}$; P:S ratio, $0.53(80)$. This diet consisted of conventional foods (Appendix 3). Menus and recipes were developed to provide variation in the diet (Appendices 4 and 5). However, the foods provided remained constant. In addition, a muffin which had the same caloric distribution as the diet was developed to supplement the diet in order to keep the subjects' weight stable (Appendices 6 and 7). Muffin con- 
sumption was determined by first feeding. 6 muffins (950 calories) to each subject as compensation for the $10 \mathrm{miles}$ run daily. Muffins were then adjusted on an individual basis in order to maintain body weight. The final caloric distribution during the baseline period was 53\% carbohydrate, $15 \%$ protein, and $32 \%$ fat.

A11 food and ingredients were weighed, on a Metler scale prior to meal preparation. The only foods that were consumed freely were water, black téa or coffee, diet soda, saccharin, and lemon. Breakfast and dinner were served in a dining room in a relaxed and social setting. At dinner, a salad bar was provided (Appendix 8). The 'subjects were allowed to consume as much salad as desired with calorie-free vinegrette dressing. Salad consumption was recorded, calculated, and added to the baseline diet. Breakfast and dinner were scheduled at the convenience of the subjects. Lunches were packed and taken after breakfast by the subjects to be eaten at their place of employment. The subjects were questioned daily for any problems, that they might have had during that day. The subjects were supervised during meals by the investigators and were under the scrutiny of an attending physician.

\section{THE HYPOCALORIC PERIOD}

A 10-day hypocaloric period followed the 7-day baseline period. During this period, the subjects continued to run 10 miles daily and to consume the baseline diet. Since the 
energy needs for running 10 miles are approximately 950 kcal/day or $95 \mathrm{kcal} / \mathrm{mile}$ run (81), caloric intake was reduced by approximately $95 \mathrm{kcal} / \mathrm{mile}$ run. This reduction was achieved by the removal of 950 calories via the muffin supplement; however, the caloric distribution and P:S ratio romained constant.

\section{ANTHROPOMETRIC DETERMINATION}

The heights of the subjects were measured one week prior to the study. They were weighed each morning in their running shorts before running and prior to eating breakfast. Pectroal, axial, abdominal, and suprailium skinfolds were. measured with Lange calipers on days 1,8 , and 18. Percent body fat was calculated by the procedure of Pollock et al. (82). The equation is as follows:

$$
\begin{gathered}
x_{1}=\sum \text { of skinfolds (mm) } \\
x_{2}=\operatorname{age~}(y r s)
\end{gathered}
$$

body fat $=0.27784\left(x_{1}\right)-.00053\left(x_{1}\right)^{2}+0.12437 .\left(x_{2}\right)-$ 3.28791

Fat weight was calculated by multiplying percent body fat by body weight. The fat weight was then subtracted from body weight to determine lean body. weight.

\section{BIOCHEMICAL DETERMINATIONS}

Phlebotomy occurred when subjects'were in a fasting- 
resting state. Forty cc of blood were drawn from each subject and centrifuged by a licensed medical technician. Only $30 \mathrm{cc}$ were drawn on day 10 since HDL-2 and HDL-3 were not measured on that day while an additional $20 \mathrm{cc}$ were drawn on days 8 and 18. HDL-cholesterol, HDL-2, and HDL-3 subfractions, and Apo A-I were analyzed at the Nutrition and Metabolism Research Laboratory at the Miriam Hospital, Providence, Rhode Island. Methodologies for these analyses are referenced in Appendix 9.

Muscle metabolites including CPK, BUN, UUN, and urinary creatinine were determined to indicate any lean muscle mass. breakdown. These tests were performed by the investigator at the Nutrition Laboratory at the University of Rhode Island, Kingston, Rhode Island. Creatine Phosphokinase (CPK) levels were determined colorimetrically within 24 hours by the ADPPhosphocreatine reaction (83): To each sample tube, $0.5 \mathrm{ml}$ of the $75 \%$ phosphocreatine solution (diluted with $15 \mathrm{ml}$ of $\mathrm{MgSo}_{4}$ in Trizma buffer solution, ph 7.5) and .01 $\mathrm{m} 1$ of serum was added. Water $(0.1 \mathrm{~m} 1)$ was added and mixed. The tubes were then incubated in a $37^{\circ} \mathrm{C}$ water bath for 15 minutes. Every 15 seconds, $0.2 \mathrm{ml}$ of ADP-Glutathione solution was added, the tubes were then vortexed and incubated for 30 minutes to begin the following reaction:

$\mathrm{ADP}+$ Phosphocreatine $\stackrel{\mathrm{CPK}}{\longrightarrow} \mathrm{ATP}+$ Creatine 
Glutathione is required for the methylation of glycocyamine to form creatine (84).

Exactly 30 minutes after the addition of the ADP-glutathione, $0.2 \mathrm{~m} 1$ of P-Hydroxymercuribenzoate was added. This halted enzymatic activity and prevented the dissociation into 2 protein components without an adverse effect on activity.

Two hundred $\mathrm{mg}$ of $\alpha$ Napthol was diluted with $10 \mathrm{ml}$ of alkali solution (sodium hydroxide and sodium carbonate). One $\mathrm{m} 1$ of a $5 \%$ diacety 1 solution and $7 \mathrm{~m} 1$ of $\mathrm{H}_{2} \mathrm{O}$ were added to the tubes and they were incubated at $37^{\circ} \mathrm{C}$. for 15 minutes. At this point, the creatine reacted with the Napthol and diacetyl solutions to yield a colored complex. The tubes were çentrifuged for 5 minutes and absorbence was read on a Bausch and Lomb Spec 20 at $520 \mathrm{~nm}$.

Blood Urea Nitrogen (BUN) was determined on days 8 and 18 by the Berthelot reaction (85). To each tube was added $0.5 \mathrm{ml}$ of a urease buffer solution and $10 \mu 1$ of serum. The tubes were mixed and incubated in a $37^{\circ} \mathrm{C}$ water bath for 10 minutes. In this reaction, urea is hydrolyzed by urease to ammonia and carbon dioxide as follows:

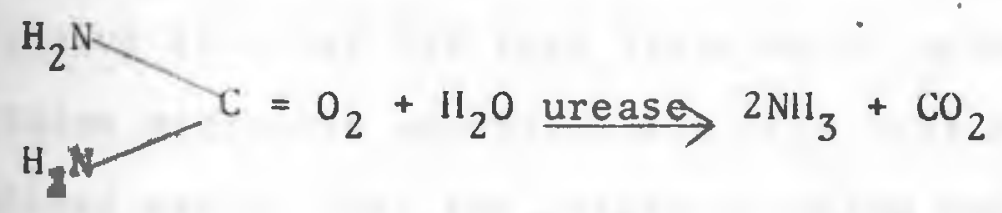

One $\mathrm{ml}$ of phenol nitroprusside reagent $\left(50 \mathrm{~g} / 1^{\circ}\right.$ sodium nitroprusside plus stabilizer), $1.0 \mathrm{ml}$ of alkaline hypo- 
chlorite $(0.2 \%$ sodium hypochlorite in alkali), and $5.0 \mathrm{ml}$ of water were added. The tubes were vortexed after each addition and color was allowed to develop for 30 minutes at room temperature. In this reaction, the alkaline hypochlorite and phenol, in the presence of the catalyst, sodium nitroprusside $\left(\mathrm{Na}_{2} \mathrm{Fe}(\mathrm{CN})_{5} \mathrm{NO} \cdot 2 \mathrm{H}_{2} \mathrm{O}\right)$, formed indophenol (blue). The concentration of ammonia is directly proportional to the absorbence of indophenol:

$$
\begin{aligned}
& \mathrm{NH}_{3}+\mathrm{OCl}^{-}+2 \stackrel{\mathrm{OH}}{ } \text { Sodium Nitroprusside } \\
& 0=\Longleftrightarrow+N \not 3-0 \\
& \text { Indophenol }
\end{aligned}
$$

The absorbence was read at $570 \mathrm{~nm}$.

On days 7 and 17 , the subjects were instructed, to void into sterile containers over a 24 hour period. Urine volumes were subsequently estimated. Seven $\mathrm{ml}$ of $37 \% \mathrm{HCL}$ was added to each sample and the samples were frozen: Urinary urea nitrogen was determined by the Berthelot method (85). Ten $\mu 1$ of a $100-$ fold dilution of urine and $0.5 \mathrm{~m} 1$ of urease were placed in duplicate tubes. All other steps were identical to the method used to measure BUN levels. A third tube containing $10 \mu 1$ of 100 -fold dilution of urine was used to determine preformed ammonia. For this test all steps were identical except that the urease solution was added after the addition of phenol nitroprusside and alkaline hypochlorite reagents. The nitrogen values calculated for the 
third tube, when subtracted from that of the original duplicate tubes, yielded the corrected urine urea nitrogen concentration.

Urinary creatine levels were also determined from 24hour urine samples on days 8 and 18 , by the alkaline picrate method (Jaffe reaction) (86). In this assay, $8 \mathrm{ml}$ of water were dispensed into tubes with $2 \mathrm{ml}$ of $1: 1$ picric acid- $\mathrm{NaOH}$ solution and $20 \mu 1$ of urine. The mixture was vortexed, and allowed to stand at room temperature for 20 minutes to form the color complex. Absorbence was read at $520 \mathrm{~nm}$.

\section{MAXIMUM OXYGEN UPTAKE}

Aerobic capacity of the runners was determined during exercise on a bicycle ergometer by direct measurement of maximum oxygen uptake $\left(\mathrm{VO}_{2} \mathrm{max}\right)$. This test was performed at the Human Performance Laboratory at the Miriam Hospital. $\mathrm{VO}_{2} \max$ is considered to be the best measure of the oxygen transport system, as well as the most commonly used measure of cardiorespiritory fitness (82). Additionally, it correlates well with success in endurance sports (82).

Heart rates were monitored with an electrocardiograph and recorded every minute. The cycle ergometer was calibrated prior to testing with a $1 \mathrm{~kg}$ weight. Pedal rate was kept constant at $.50 \mathrm{rpm}$ with a metronome. $\mathrm{VO}_{2}$ was measured with a pneumotachograph (Hewlett-Packard) and an S3-A oxygen analyzer (Applied Elecetrochemistry, Inc.). The initial exercise rate was, $150 \mathrm{kpm}-\mathrm{min}^{-1}$ which was increased 150 
kpm-min ${ }^{-1}$ every minute. Maximum $\mathrm{O}_{2}$ uptake was considered to have been reached when the difference between 2 consecutive measurements was $<250 \mathrm{~m} 1-\mathrm{min}^{-1} \cdot \mathrm{VO}_{2} \max \left(1-\mathrm{min}^{-1}\right)$ was estimated from the Astrand-Rhyming nomogram using the mean steady-state heart rate and the final exercise rate (87).

\section{STAT ISTICAL ANALYSIS}

Group mean and standard deviations were dețermined on all dietary, biochemical, anthropometric, and physiological parameters. Absolute and percent mean differences between days 7 and 17 for dietary data and between days 8 and 18 for all other data were determined. Mean differences by day were determined for body weight, percent body fat, and lean body weight. The student $t$ test was used to determine the significance of changes in body weight, percent body fat, lean body weight, HDL, HDL-2, HDL-3, and Apo A-I.

Analys is of variance, determined with general linear models, measured the significance of difference in weight by day and subject. Pearson product moment formula were used to determine the correlation between biochemical, dietary, anthropometric, and physiological parameters on days.7 and 17 , or on days 8 and 18 .

Regression analysis was performed between muscle metabolite values and other parameters to predict any relationships between variables. These. statistical analyses were performed using SAS pack \# 79.6 . 


\section{SCOPE OF THE STUDY}

This study is part of a larger study, "Lipoproteins in Active Men: The Role of Exercise and Diet." The grant \#R01, HL, 26697-01, was awarded by the National Heart, Blood, and Lung Institute (NHBLI), to Miriam Hospital and subcontracted to the University of Rhode Island. 


\section{RESULTS AND DISCUSSION}

\section{DESCRIPTION OF SUBJECTS}

Sixteen male endurance athletes, 20 to 45 years of agé, participated in this 18-day study. They had a mean height of $69.2 \pm 2.4$ inches; a mean initial body weight of $153.2 \pm$ 16.1 pounds and a mean initial percent body fat of $8.9 \pm$ $3.0 \%(\mathrm{Tab} 1 \mathrm{e} 1)$.

\section{THE BASELINE PERIOD (DAYS $1-\underline{7}$ )}

DIETARY DATA

The athletes consumed the baseline diet together with salad, and muffin supplements for a period of 7 days. The mean caloric intake during this period was $3757+409$. The caloric and fat distribution was as follows: carbohydrate, $53 \%$, protein $15 \%$, and fat, $32 \%$. The $\mathrm{P}: \mathrm{S}$ ratio was 0.53 (Table 2). The calorie level of the baseline diet maintained mean body weight. The baseline diet was used to establish baseline lipid levels for determining the effects of dietary intervention.

\section{ANTHROPOMETRIC DATA}

During this period, a very slight weight loss of 0.45 lbs. occurred (Table 3 ). A $2 \%$ decrease in lean body weight (1.64 lbs.) also occurred (Table 3). This may have been due to a loss of water, protein, and/or glycogen. Research has 
indicated that during intense exercise and normal dietary conditions, muscle glycogen stores are an important source of energy (88). Therefore, training improves the capacity of the muscles to generate energy aerobically. In addition to an increase in muscle glycogen depletion. with training, there is an increase in muscle glycogen stores (81).

Percent body fat increased by $0.63 \%$ ( $p<.002)$ (Table 3). Although the weight loss apparently was not due to percent fat loss, this increase in body fat is difficult to explain. It may have been due to normal fluctuations in body fat, or the fact that the caloric intake of some of the subjects during the baseline period exceeded their requirements. For example, although the mean change in weight indicated a slight loss of body weight, 7 individuals gained a mean of 1.20 lbs. Another possibility is that an increase in percent fat was the net result of the decrease in lean body weight.

\section{BIOCHEMICAL DATA}

\section{SERUM LIPIDS}

The mean serum HDL, HDL-2, HDL-3 and APO A-I values of the runners are presented in Table 4. The initially elevated HDL levels in these athletes (66.9 $\mathrm{mg} / \mathrm{dl})$ are comparable to those levels found in physically active men in previous studies $(9,41)$. The marathon runners in one study (9) had HDL levels of $58.0 \mathrm{mg} / \mathrm{dl}$ while in another study (41), the mean HDL levels of 23 active men who had 
been training for 5 years was $68.5 \mathrm{mg} / \mathrm{d} 1$.

Miles run has been shown to be a significant predictor of HDL levels $(9,39)$. This was reflected in the 50 miles/ week run during the preceding year and the $70 \mathrm{miles} /$ week run in the 2 weeks prior to the study by the subjects.

During the baseline period, HDL levels remained approximately the same while HDL-2 increased $4.80 \mathrm{mg} / \mathrm{d} 1$, and HDL3 decreased $4.40 \mathrm{mg} / \mathrm{dl}$. The fact that the HDL-2/HDL-3 ratio remained constant was indicative of a lack of change in total HDL. The decrease of $5.40 \mathrm{mg} / \mathrm{dl}$ in APO A-I was unexpected since APO A-I levels are usually indicative of circulating HDL (22). The rate of synthesis and or catabolism of the apoproteins have been proposed as determinants of HDL levels (22). However, between day 1 and day 8 , the change in APO A-I did not appear to affect HDL levels. Therefore, the baseline diet which was representative of habitual diet did not appear to affect the mean total HDL level.

\section{MUSCLE METABOLITES}

Muscle metabolites were measured to observe the effects of exercise on lean muscle mass while the subjects consumed the calories necessary to maintain body weight. Since these subjects consumed what was intended to be representative of their habitual dict, the results were reflective of exercise rather than diet.

Urea, the major nitrogen containing end product of protein catabolism, may be reabsorbed into the tubes by passive 
diffusion and a sudden decrease in fractional excretion of urea can be observed if urine flow is abruptly decreased (89). Studies have shown that at normal urine flow, rough1y $50 \%$ of the filtered urea is reabsorbed in mamma1s, secreted, and recirculated (89). Therefore, urea levels in urine and serum are reflective of a number of circumstances including urine flow.

The urea levels measured on day 8 reflect the baseline period. According to the literature, the normal BUN range is $7-18 \mathrm{mg} / 100 \mathrm{ml}$ and the normal UUN range is $12-20 \mathrm{gm} / 24$ $\mathrm{hr} .(90)$. Both mean BUN $(28.8 \mathrm{mg} / 100 \mathrm{ml})$ and UUN $(26.0 \mathrm{gm} /$ $24^{\circ} \mathrm{hr}$. ) in these athletes exceeded the normal ranges. However, the mean $24 \mathrm{hr}$. urine volume fell within the normal range (91) (Table 5). These data, indicate that the elevated BUN and UUN levels were not due to excessive urine flow but to other factors.

Diet and exercise also affect urea nitrogen levels. During the baseline period, the diet consumed by the runners was reflective of habitual dietary intake. Although the diet aimed to keep weight constant, the slight loss of weight during this period may have been due to increased protein catabolism. Since the amount of urea formed in the fullgrown individual is approximately proportional to nitrogen intake (92), the protein content of the diet may have been slightly lower than was necessary for energý balance. Additionally, studies have shown increased BUN levels with prolonged exercise $(93,94,95)$. During exercise, 
nitrogen containing compounds such as urea play a direct role in the energy yielding process. Increased degradation of nitrogen containing products will occur with the general enhancement of the metabolic process during exercise. Some researchers $(93,94,96)$ suggest that elevated BUN levels during exercise may be due to hypohydration. It is apparent from the aforementioned studies, that the elevated BUN levels of the subjects during the baseline period are a result of high levels of physical activity. Dohm et al. (97) reported increased UUN excretion as a result of training, as well as increased protein catabolism due to increased energy need. The elevated UUN levels of these athletes agree with the results of Dohm and are probably a result of increased physical activity. The urinary creatinine, as we 11 as the CPK levels that were determined on day 8 , were reflective of the baseline period. Creatinine is derived from muscle breakdown and is a waste.product of creatine or creatine phosphate (CP), the precursor of creatine in muscle. CP serves as a source of energy for muscular contraction. Formation of ATP, the primary energy source for muscular activity is formed by the catalytic action of the enzyme CPK and creatine from CP and ADP (98). Research has shown that the amount of creatinine present in the urine is an index of lean body mass (99). The normal range for creatinine excretion is 1.0 $-2.0 \mathrm{gm} / 24 \mathrm{hr} .(90)$. The mean creatinine level for day 8 was $2.97 \mathrm{gm} / 24 \mathrm{hr} . \pm 0.84$. This elevated level was probably 49 
due to the high level of physical activity. Refsum et al. (95) observed a $60 \%$ increase in creatinine in trained athletes after several days of cross country skiing. CPK levels in athletes may vary due to a number of factors. Researchers have noticed that CPK levels are higher in males than females (91). Elevated CPK levels have also been observed during physical exercise (100). During physical activity, there is a higher energy demand for muscle contraction, therefore, an increased need for ATP and subsequent CPK activity. The normal range for serum CPK levels is 0-12 nmol creatine/min., borderline: 12-20 nmol creatine/min., and elevated: over 20 nmol creatine/min. (83). On day 8 of the study, the mean CPK level was $16.5 \pm 6: 40 \mathrm{nmol}$ creatine/min. at $25^{\circ} \mathrm{C}$ (Table 5). Therefore, this value was within the borderline range. The high levels of physical activity of the subjects again appeared to have influenced the CPK value.

A previous investigator (100) concluded that prolonged exercise can lead to increased serum $C P K$ activity as a result of increased release of the enzyme from muscle tissue. In another study, a population of 6 trained runners were examined before and after a $42.2 \mathrm{~km}$ race. CPK levels rose 2 -fold (96). CPK values often are dependent on the type of activity (101). Aerobic sports, such as running do not effect.CPK as much as anaerobic sports. Aerobic sports rely on the aerobic generation of ATP through fat and carbohydrate oxidation, while anaerobic sports rely more on the 
anaerobic mechanism of increasing ATP, such as the action of CPK on CP (101). This may be another reason for the borderline CPK values. It can be concluded that during the baseline period for these subjects, exercise resulted in high levels of muscle metabolites with a subsequent slight loss of lean body weight.

\section{THE HYPOCALORIC $\underline{\text { PERIOD }}$}

DIETARY AND ANTHROPOMETRIC DATA

During the hypocaloric period, the subjects lost body weight by metabolizing their own tissues for energy due to a lack of food energy. To achieve negative energy balance, the calories necessary' to accomplish a $31 \mathrm{~b}$. weight loss over 10 days were determined from the number of calories expended during 10 miles of daily running and the calories consumed during the baseline period. In order to achieve the 3.42 lbs. of weight loss during the experimental period, calories were reduced from $3757 \mathrm{kcal} / \mathrm{day}$ to $2821 \mathrm{kcal} / \mathrm{day}$; a percent difference of $25 \%$ (Figure 1 ). The final distribution of calories in the hypocaloric diet was $55 \%$ carbohydrate, $16 \%$ protein, and $32 \%$ fat. It therefore took a deficit of $936 \pm 41.9$ calories to 10 se $3.42 \mathrm{lbs}$. of weight. of these calories, $444 \pm 20$ kcal were from carbohydrate, $128 \pm 7.6 \mathrm{kcal}$ were from protein, and $333 \pm .63 \mathrm{kcal}$ were from fat (Table 2). Despite the very low percentage of body fat of these subjects, body weight was lost at approximately 
the same rate (1.0 1b./3500 kcal) as the normal, sedentary individual. The mean weight loss over the 18-day period was $3.87 \mathrm{lbs}$. (Figure 2). According to analysis of variance, the weight loss was significant by day $(\mathrm{p}<0.0001)$ and.by individual $(\mathrm{p}<0.0001)$.

Energy for muscular activity may come from a number of sources. The obvious source is the caloric content of the diet. However, when caloric intake is inadequate, other sources are necessary. First, energy may be derived from adipose tissue, in which fatty acids are hydrolyzed from triglycerides, transported, and utilized. Another source is muscle glycogen which may be broken down to glucose and used for energy. Additionally, ADP and CP can form ATP and creatine in the muscle cell. ATP is then utilized for energy (98). Lastly, muscle protein, proteins in adipose tissue, or intramuscular lipids may be catabolized for energy (102).

Mean percent body fat decreased significantly $(\mathrm{p}<$ 0.0001 ) from $9.54 \pm 3.3$ to $8.62 \pm 3.3$ (Figure 3 ). This decrease resulted in a $0.92 \% 10 \mathrm{~s}$ of body fat $(\mathrm{p}<0.001)$ (Table 3). A positive correlation was observed between mean change in weight from days 8 to 18 and change in percent body fat $(\dot{r}=0.6211, p<.01)$. The reduction in calories between day' 8 and 17 was not.significantly corre1ated with change in percent body fat between day 8 and 18 $(r=-0.0920, p<0.73)$.

Although no significant correlation was evident, a loss 52 
of body fat with reduced caloric intake and exercise is predictable. Several researchers have observed the loss of percent body fat with caloric restriction and exercise (2, $11,14,15,65$ ).

Lean body weight decreased from $137.6 \pm 12.3 \mathrm{lbs}$. to $135.9 \pm 12.1 \mathrm{lbs}$. (Figure 4). This decrease of $1.21 \mathrm{bs}$. was significant $(\mathrm{p}<0.0001)$ (Table 3). However, the loss of lean body weight was not significantly correlated with a decrease in mean body weight $(r=0.316, p<0.23)$ nor a decrease in calories $(r=-0.068, p<0.80)$.

\section{BIOCHEMICAL DATA}

\section{SERUM LIPIDS}

The mean HDL, HDL-2, HDL-3, and APO A-I values for days 8 - 18 are presented in Table 4. Figure 5 shows a plot of the mean HDL levels during the 18-day period. Beginning on day 8 , the HDL levels increased steadily until day 18 when it decreased slightly which may represent a stabilizing effect. A $4.80 \mathrm{mg} / \mathrm{dl}$ increase in HDL-2 levels was observed from day 8 to day 12 at which time it appeared to stabilize (Figure 6). HDL-3 decreased $3.70 \mathrm{mg} / \mathrm{dl}$ from day 8 to 12 while on day 15 it increased slightly (1.8 mg/. d1) and then decreased $1.3 \mathrm{mg} / \mathrm{dl}$ on day 18 (Figure 7). APO A-I decreased from day 8 to day 10 by $2.0 \mathrm{mg} / \mathrm{dl}$, then increased again steadily to approximately the same level on day 18 as on day 8 (Figure 8.) 
The hypocaloric diet did affect the mean HDL levels. Since the nutrient composition in the hypocaloric diet was the same as that in the baseline diet, it can be assumed that the reduction in calories was responsible for changes in HDL levels.

HDL increased $4.90 \mathrm{mg} / \mathrm{dl}(\mathrm{p}<.001) ; \mathrm{HDL}-2,7.40 \mathrm{mg} / \mathrm{d} 1$ $(\mathrm{p}<.001)$; while HDL -3 decreased $3.20 \mathrm{mg} / \mathrm{d} 1 \quad(\mathrm{p}<.01)$ (Figure 9). The increase in HDL levels with weight loss during this study coincides with the results of other studies which combined a hypocaloric diet with exercise $(8,56)$. However, these studies observed obese individuals in contrast to the lean subjects in the present study. Neverthe = less, these data indicated that 1oss of weight may be responsible for the increase in HDL levels.

Relative body weight was shown to be the best predictor of HDL levels in a population that was at high risk for coronary heart disease (6), as well as in physically active men (9). However, in the present study no significant relationship was observed between body weight and HDL ( $r=$ $-0.333, \mathrm{p}<0.21)$, between body weight and HDL-2 $(\mathrm{r}=$ $-0.256, p<0.338)$, or between body weight and HDL-3. ( $r=$ $-0.230, p<0.392)$. Also, the decrease in calories during the hypocaloric period was not significantly related to HDL $(r=0.450, p<0.87)$, to HDL $-2(r=-0.089, p<0.74)$, or to HDL-3 $(r=0.086, p<0.75)$. Since previous studies (8, $12,56)$ have attributed an increase in HDL to a decrease in body weight, the lack of a significant correlation between 
these parameters in the present study may be due to the brevity of the study or to the number of the subjects. A significant correlation may have existed if the experimental period had been extended and if the weight loss had been stabilized.

Another possible variable is the difference. in the effect of diet and exercise on HDL levels in lean vs. the obese subjects: HDL levels have been shown to be inversely correlated with body weight as well as adiposity $(9,52)$. In this study, change in body weight was not significantly correlated with HDL $(r=-0.33, \mathrm{p}<0.21)$ nor was change in percent body fat $(p<0.91)$.

The effect of the hypocaloric diet on the subfractions of HDL are presented in Figure 9. HDL-2 appears to follow a trend similar to that of HDL, while HDL-3 levels decreased. A significant correlation was observed between HDL and HDL-2 $(r=0.865, p<.0001)$; HDL and Apo A-I $(r=0.612, p<$ $.01)$ but not between HDL vs. HDL-3 $(r=0.359, p<0.1)$. Fluctuations in HDL were largely due to variations in HDL2 (23).

Although Apo A-I fluctuated throughout the period (Figure 8), there was no significant change in Apo A-I at the end of the 10 days of caloric restriction. The fact that Apo A-I remained constant is of interest. IBDL- 2 is. richer in lipids and Apo A-I than HDL-3 which is comprised of $50 \%$ Apo $E$ and a small amount of Apo A. The 1ack of change in Apo A-I levels may have been due to the decrease in the 
Apo A-I portion of HDL-3 during HDL maturation which may have been counterbalanced by, an increase in HDL-2 since a significant correlation was observed between HDL -2 and Apo A-I $(r=0.654, p<.006)$. This is supported by other studies $(22,29)$.

\section{MUSCLE' METABOLITES}

On day 18 , muscle metabolites were measured to determine if any change in lean body weight was due to a change in muscle. $\mathrm{CPK}$ increased from $16.5 \pm 6.4$ to $26.7 \pm 10.7$ nmol creatine/min, at $25^{\circ} \mathrm{C}$, while BUN decreased from $28.8 \pm$ 7.2 to $21.9 \pm 5.6 \mathrm{mg} / 100 \mathrm{~m} 1$. UUN also decreased from 26.0 \pm 9.1 to $21.8 \pm 10.6 \mathrm{gm} / 24 \mathrm{hr}$. A decrease in creatinine from $2.97 \pm 0.84 \mathrm{gm} / 24 \mathrm{hr}$. to $2.73 \pm 0.84 \mathrm{gm} / 24 \mathrm{hr}$., was observed (Table 5). The change in body weight between day 8 and 18 was not significantly correlaţed with either a change in serum CPK, $(r=-0.439, p<0.409), B U N,(r=$ $-0.190, p<0.481)$, UUN, $(x=-0.045, p<0.874)$, or

creatinine, $(R=0.229, p<0.41)$. The decrease in calories during the hypocaloric period also was not significantly correlated with change in CPK, $(r=0.195, p<0.41), B U N$, $(r=-0.119, p<0.66)$, UUN, $(r=0.182, p<0.52)$, or creatinine, $(R=-0.290, p<0.46)$.

Several studies have investigated the results of exercise and a hypocaloric diet on lean body mass $(11,13,14)$. Some researchers have demonstrated an increase in lean body mass $(13,14)$, while others have reported a decrease in lean 
body mass $(11,14)$, with caloric restriction and exercise. This study has shown a significant decrease in lean body weight, and the components of that loss appear to be due to a loss of muscle mass. CPK levels at the end of the hypocaloric period were well above the normal range, On the other hand, UUN and BUN decreased significantly while creatinine excretion decreased slightly.

Regression analysis was used to determine any relationship between BUN, UUN and lean body weight, as well as be-. tween other parameters in this study. BUN was not significantly related to lean body weight $(\mathrm{p}<0.50)$, to caloric intake $(\mathrm{p}<0.74)$, to body weight $(\mathrm{p}<0.25)$, or to percent body fat $(p<0.31)$. UUN was also not significantly related to lean body weight $(\mathrm{p}<0.16)$, to cáloric intake $(\mathrm{p}<0.71)$, to body weight $(p<0.28)$, or to percent body fat $(p<0.25)$. During caloric restriction and exercise, several researchers have observed effects on these metabolites (103, $104,105)$. Investigators did not observe enhanced protein catabolism in a group of untrained males consuming hypocaloric diets (103). UUN excretion of these subjects decreased while creatinine excretion remained unchanged. These researchers concluded that during exercise, when caloric intake was restricted, carbohydrate and fatty acids were the major source of energy for muscular work rather than muscle protein (103).

Another study observed male athletes who had lost weight and whose body fat was either not measurable or 
extremely low. Although on some days they were in negative nitrogen balance, UUN excretion remained stable throughout the study. The authors concluded that nitrogen was conserved during, heavy exercise to permit them to maintain high exercise activity without increasing the rate of utilization of their only body store of energy, lean muscle mass (104). In this present study, it appeared that the decrease in muscle metabolites during the hypocaloric period may have been'a function of the nitrogen sparing effect observed in the previous study. In addition to a decrease in total calories, part of the caloric deficit was due to a decrease in dietary protein. In fact, $31.9 \mathrm{gm}$ of protein or $194 \mathrm{mg}$ of nitrogen were removed from the baseline diet (Table 2). In addition to the suggested protein sparing effect, nitrogen intake decreased, which may explain the decrease in nitrogen containing metabolites.

In one study, urea nitrogen levels were found to vary proportionately with dietary nitrogen intake. The investigators concluded that these proportional changes were due to changes in glomerular filtration rate. In addition, they claimed that UUN varied with urine flow (92). In the present study, mean urine volume increased slightly during the hypocaloric period. If total nitrogen output, as in feces, sweat, and urine, had been determined, nitrogen balance could have been calculated and then may have reflected this relationship between nitrogen intake and nitrogen excretion. 
In this study, the decrease in dietary nitrogen (21\%) was greater than the decrease in UUN (12\%). Correlation was observed between the difference in nitrogen intake from days 7 to 17 and the difference in UUN from days 8 to 18 . $(r=0.230, p<0.41)$. However since both decreased substantially, this may indicate a possible protein sparing effect.

The effect of the hypocaloric state on creatinine has not been well documented. According to Miller and B1yth (99), no evidence exists to indicate that excretion varies with dietary protein intake. The results of creatinine excretion in this study agree with this conclusion. A1though the protein content of the diet decreased $23 \%$ during the hypocaloric period, creatinine excretion did not change significantly. Buskirk et a1. (14) showed that a loss of muscle mass was positively correlated with creatinine excretion. However, in the current study, loss in lean body weight.was not correlated with creatinine excretion ( $\mathrm{r}=$ $0.185, \mathrm{p}<0.50)$. Also regression analysis indicated that no significant relationship was observed between creatinine and calories, $(\mathrm{p}<0.53)$, with body weight, $(\mathrm{p}<0.73)$, and with percent body fat, $(p<0.96)$.

CPK leve1s increased significantly during the hypocaloric period although the muscle metabolites decreased. Regression analysis showed significance between change in serum CPK leve1s and change in lean body weight, $(p<0.04)$ and with change in percent body fat, $(p<0.04)$. No sig- 
nificance was apparent however, with change in calories, $(p<0.73)$, and with change in body weight $(p<0.25)$. This increase appears to be due to prolonged high muscular activity levels and perhaps to an increase in muscle protein turnover rate. Muscle protein turnover rate may. have been determined by measuring 3 -methyl histidine, a free amino acid found in muscle.

$\mathrm{VO}_{2} \max$ increased during the hypocaloric diet from 53.6 to $55.2 \mathrm{m1-kg-min.}{ }^{1}$. This may not represent a true increase and may be due to error since there is a $10-15 \%$ margin of error in this estimation. However, an increase in $\mathrm{VO}_{2}$ max occurs as a result of the increased number of mitochondria and increased oxidative capacity of the muscle wi.th increased exercise (87). We11-trained athletes differ in their utilization of carbohydrate and fat within overa11 energy production. More fatty acids from adipose stores are utilized ata greaterintensity, thus saving carbohydrate stores (105).

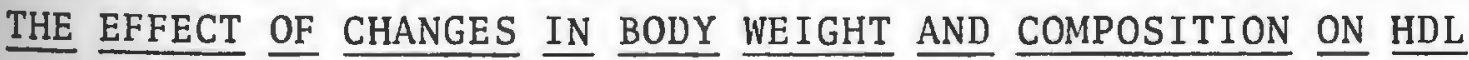

The effects of weight loss resulting from a hypocaloric diet together with exercise and subsequent changes in body composition on HDL levels may be explained by the in vitro synthesis of HDL. LPL, the enzyme responsible for the lipolysis of VLDL and chylomicrons appeared to be stimulated by weight loss $(69,-70)$. This enzyme resides in both adipose tissue and skeletal muscle with higher activity levels being 
found in adipose tissue than in skeletal muscle (27).

As seen in previous studies $(12,13)$, reduced caloric intake with subsequent weight loss may be partially responsible for increased HDL. As body weight and fat was last, LPL activity was stimulated, causing increased lipolysis of VLDL, decreased serum triglycerides, and an increase in HDL concentration. Whether increased HDL production is a function of adipose tissue LPL and/or muscle LPL stimulation is yet to be discovered.

In addition, LPL activity and subsequent HDL synthesis has been shown to be higher in male athletes than in controls $(74,32)$. These studies observed that there were positive significant correlations between distance run and adipose tissue LPL activity, and HDL levels, as well as a significant negative correlation between serum VLDL-triglycerides and muscle LPL activity. These data give additional support to increased HDL with exercise, as well as increased LPL in individuals with lower relative body weight, lower percent body fat, and higher lean body tissue than inactive individuals $(44,64)$.

In this study, changes in HDL, HDL-2, HDL-3, and APO A-I during the hypocaloric period were not correlated with changes in percent body fat, $(r=0.031, \mathrm{p}<0.91 ; \mathrm{r}=$ $0.213, \mathrm{p}<0.43 ; \mathrm{r}=0.230, \mathrm{p}<0.39),(\mathrm{r}=0.273, \mathrm{p}<0.31)$ respectively. The lack of a significant correlation may have been due to an inadequate time period of caloric restriction. These data do indicate that the increase in HDL 61 
and HDL-2 during the hypocaloric period appear to be due to the decrease in caloric intake, the loss of weight, the decrease in percent body fat, and a slight decrease in lean body mass. 


\section{SUMMARY AND CONCLUSION}

The sixteen male endurance athletes who participated in this study ran 10 miles daily during the 18-day protocal. The protocal consisted of a 7-day baseline diet which was designed to maintain body weight, followed by a 10-day hypocaloric diet. Analysis of variance indicated a significant weight loss during the 10-day hypocaloric period by day and by.subject. The student $t$ test revealed a significant increase in percent body fat during the baseline period and a significant decrease in percent body fat and lean body weight after caloric restriction and weight.loss. A significant correlation was observed between change in body weight and change in percent body fat from day 8 to 18 .

Muscle metabolites were measured in serum and 24 hour urine collections on days 8 and 18. BUN, UUN, and urinary creatinine leve1s, as we11 as serum CPK levels were elevated on day 8. After 10 days of caloric restriction, CPK continued to increase while BUN and UUN decreased. There was also a slight but insignificant decrease in creatinine. No significant relationship exists between change in body weight with CPK, UUN, BUN, nor creatinine. Additionally, there was no significance between change in UUN and dietary nitrogen intake and in creatinine and lean body weight between day 8 and 18 of the study. Linear regression analysis indicated only a significant difference between change in percent body fat and CPK and with change in lean body weight and CPK. 
The initial HDL levels of this group were elevated above the normal range due to a high level of activity. The mean HDL levels remained the same during the baseline period: HDL- 2 increased, while HDL-3 and APO A-I decreased, Following caloric restriction and weight loss, mean HDL and HDL-2 increased significantly, HDL-3 decreased significantly while APO A-I remained unchanged. A significant correlation existed between the change in HDL, and HDL-2, as we11 as between HDL- 2 and APO A-I. Accordingly, HDL-2 and APO A-I levels are predictive of levels of total HDL.

The caloric deficit required for the reported weight loss in these subjects was equal to the decrease in calories needed to lose a similar amount of weight in a sedentary population with an average percent body fat (males). It can be concluded that in this group of athletes, who had a low percentage of body fat and high amount of lean muscle mass, calories were metabolized at a rate similar to that in a norma1, non-active population.

As weight was lost due to caloric restriction and exercise, body fat and lean muscle mass were decreased. Although there was no significant correlation between change in HDL and change in body weight, percent body fat, and lean muscle mass, it appeared that as weight was lost due. to caloric restriction and exercise, HDL increased. Additionally, the loss of body fat and lean muscle mass may be influential in stimulating adipose tissue and/or skeletal muscle LPL activity and thus initiating an increase in serum HDL. 64 
Further research is needed to determine if a loss of adipose tissue and lean muscle mass with caloric restriction and exercise causes an increase in HDL by stimulating LPL activity. Additionally, it is recommended that any future study should be of longer duration and contain a larger population. It is further suggested that the basal metabolic rate plus activity level of individual subjects be calculated to determine caloric needs. Proximate analysis, fatty acid, and cholesterol analysis of foodstuffs. would have aided in more accurately determining dietary intake, since the composition of foods will vary with such factors as seasonal changes and packaging. In addition, it is recommended that, absolute depletion of muscle glycogen stores be measured directly from the muscle as opposed to determining it from $\mathrm{VO}_{2}$ max. A daily check on ketone excretion would also have indicated the adequacy of caloric intake and body fat breakdown. 


\section{REFERENCES}

1. Ross R, Glomset A. The pathogenesis of atherosclerosis I. N Engl J Med 1976;295:369-75.

2. Shekelle RB, Shyrock, AM, Oglesky P, Lepper M, Stamler $J$, Lui S, Raynor WJ. Diet, serum cholesterol, and death from coronary heart disease. The Western Electric study. N Eng1 J Med 1981;304:65-70.

3. Ball KP. Is diet an essential risk factor for coronary hear disease? Post Grad Med 1980;56:585-92.

4. Keys A, Anderson JT, Grande F. Serum cholesterol response to changes in the diet II. The effect of cholesterol in the diet. Metabolism 1965;14:759-64.

5. Miller GJ, Miller NE. Plasma high density lipoprotein concentration and development of ischaemic heart disease. Lancet $1975 ; 1: 16-19$.

6. Keys A. Alpha lipoprotein (HDL) cholesterol in the serum and risk of coronary heart disease and death. Lancet $1980 ; 1: 603-6$.

7. Gordon T, Castelli W, Hjortland MG, Kannel WB, Dawber TR. High density lipoprotein as a protective factor against coronary heart disease. The Framingham study. Am J Med 1977;62:704-14.

8. Contaldo F, Strazzul1o P, Postiglione A, Riccardi G, Patti L, Di Biase G, Mancini M. Plasma high density lipoprotein in severe obesity after stable weight loss. Atherosclerosis $1980 ; 37: 163-67$.

9. Hartung GH, Foreyt JP, Mitche11 RE, Vlasek J. Gotto AM. Relation of diet to high-density lipoprotein cholesterol in middle-aged marathon runners, joggers, and inactive men. N Eng1, J Med 1980;302:357-61.

10. Wood PD, Haskell W, Klein H, Lewis S, Stern MP, Farquhar JW. The distribution of plasma lipoproteins in middleaged male runners. Metabolism 1976;25:1249-57.

11. We1tman A, Matter S, Stamford B. Caloric restriction and/or mild exercise: effects on serum lipids and body composition. Am J C1 in Nutr 1980;33:1002-9. 
12. Thompson PD, Jeffery RW, Wing RR, Wood PD. Unexpected decrease in plasma high density lipoprotein cholesterol with weight $10^{3} s$. Am J Clin Nutr $1979 ; \because 32: 2016-21$.

13. Leon AS, Conrad J, Hunninghake DB, Serfass R. Effects of a vigorous walking program on body composition and carbohydrate and 1ipid metabolism of obese young men. Am J C1in Nutr 1979;32:177.6-87.

14. Buskirk ER, Thompson RH, Lutwak L, Whedon GD. Energy balance of obese patients during weight reduction: influence of diet and exercise. Ann NY Acad Sci 1963;110: $918-40$.

15. Lewis S. Haske11 WL, Wood PD, Manoogian N, Bailey JE, Pereira MB. Effects of physical activity on weight reduction in obese middle-aged women. Am J Clin Nutr $1976 ; 29: 151-56$.

16. Goldstein JL, Brown MS. The low-density lipoprotein pathway and its relation to atherosclerosis. Ann Rev Biochem 1977;46:897-930.

17. Connor WE, Cerqueira MT, Connor RW, Wallace RB, Malinow MR, Casdorph HR. The plasma lipids, lipoproteins, and diet of the Tarahumara indians in Mexico. Am $\mathrm{J}$ Clin. Nutr $1978 ; 31: 1131-42$.

18. Smith LC, Pownall HJ, Gotto AM. The plasma lipoproteins: structure and metabolism. Ann Rev Biochem 1978;47:75177.

19. Levy RI. Cholesterol, 1ipoproteins, apoproteins, and heart disease: present status and future prospects. C1 in Chem 1981;27:653-62.

20. Jackson RL, Morrisett JD, Gotto AM. Lipoprotein structure and metabolism. Physiol Rev 1976;56:259-301.

21. Schonfield G, Weidman SW, Witztum JL, Bowen RM. Alterations in levels and interrelations of plasma apopolipoproteins induced by diet. Metabolism 1976;25:261-75.

22. Nicoll E, Miller NE, Lewis B. High density 1ipoprotein metabolism: Adv Lipid Res 1980;17:53-106.

23. Schaefer EJ, Foster DM, Jenkins LL, Lindgren FT, Berman 
$M$, Levy $R$, Brewer $H B$. The composition and metabolism of high density lipoprotein subfractions. Lipids 1979; $14: 511-21$.

24. Patsch JR, Gotto AM, Olivecrona T, Eisenberg S. Formation of high density lipoprotein-2 like particles during lipolysis of very low density lipoproteins in vitro. Proc. Nat1 Acad Sci 1978;75:4519-23.

25. Glomset JA. Physiological role of lecithin: cholesterol acyl-transferase. Am J C1 in Nutr 1970;23:1129-36.

26. Huttunen JK, Ehnholm C, Kekki M, Nikkila EA. Postheparin plasma lipoprotein 1 ipase and hepatic lipase in normal subjects and in patients with hypertriglyceridemia: correlations to sex, age, and various parameters of triglyceride metabolism. Clin Sci Mol Med 1976; $50: 249-60$.

27. Tan MH, Sata $T$, Havel RJ. The significance of 1ipoprotein lipase in rat skeletal muscles. J Lipid Res $1977 ; 18: 363-70$.

28. Schwartz RS, Brunzel1 JD. Increase of adipose tissue lipoprotein lipase activity with weight 1oss. J C1in Invest $1981 ; 67: 1425-30$.

29. Taskinen MR, Nikkila EA. High density lipoprotein subfractions in relation to lipoprotein lipase activity of tissues in man - evidence for reciprocal regulation of HDL- 2 and HDL- 3 levels by lipoprotein lipase. Clin Chim Acta $1981 ; 112: 325-31$.

30. Wolansky H. A proposal linking clearance of circulating lipoproteins to tissue metabolic activity as a basis for understanding atherogenesis. Circulation Res 1980;47: 301-9.

31. Ta11 AR, Sma11 DM. Plasma high density lipoproteins. N Eng1 J Med 1978;299:1232-36.

32. Nikkila EA, Taskinen MR, Rehunen S, Harkensen M. Lipoprotein lipase activity in adipose tisșue and skeletal muscle of runners: relation to serum lipoproteins. Metabolism $1978 ; 27: 1661-71$.

33. Ross R, Glomset JA. The pathogenesis of atherosclerosis 
II. N Engi J Med 1976;295:420-25,

34. Carew TE, Koschinsky T, Hayes SB, Steinberg D. A mechanism by which high density lipoproteins may slow the atherogenic process. Lancet 1976;2:1315-17.

35. Barr DP, Russ EM, Eder HA. Protein-1ipid relationships in human plasma II. In: Atherosclerosis and related conditions. Am J Med 1951;11:480-93.

36. Kanne1 WB, Caste11.i wip, Gordon $T$. Cholesterol in prediction of atherosclerotic disease. Ann Intern Med $1979 ; 90: 85-91$.

37. Wood PD, Haske11 WL. The effect of exercise on plasma high density 1ipoproteins. Lipids 1979;14:417-27.

38. Young L, Barboriak 'JJ. Exercise, diet, and high density1ipoprotein cholestero1. N Eng1 J Med 1980;303:223-24.

39. Williams PT, Wood PD, Haske11 WL, Vranizan K. The effects of running mileage ańd duration on plasma 1 ipoprotein.levels. J Am Med Assoc 1982;247:2674-79.

40. Wetzler HP. Exercise, diet, and high-density 1ipoprotein cholesterol. N Eng1 J Med 1980;303:223-24.

41. Lehtonen A, Viikari J. Serum triglycerides and cholesterol and serum high-density lipoprotein cholesterol in highly physically active men. Acta Med Scand 1978;204: 111-14.

42. Berg A, Keul J, Ringwald G, Deus B, Wybitul K. Physical performance and serum cholesterol fractions in hea1thy young men. C1in Chim Acta 1980;106:325-30.

43. Masarei JRL, Pyke JE, Pyke FS. Physical fitness and plasma HDL cholesterol concentrations in male business executives. Atherosclerosis 1982;42:77-83.

44. Vodak P, Wood P, Haske11 W, Williams P. HDL-cholesterol and other plasma lipid and lipoprotein concentrations in middle-aged male and female tennis players. Metabolism $1980 ; 29: 745-52$.

45. Smith MP, Mendez J, Druckenmiller M. Kris-Etherton PM. Exercise intensity, dietary intake, and high density 
1ipoprotein cholesterol in young female competitive swimmers. Am J C1in Nutr 1982;36:251-55.

46. Huttunen JK, Lasimies E, Voutilainen E, Pentilla I, Sutonen 0, Rauramaa R. Effect of moderate physical exercise on serum lipoproteins. A controlled clinical trial with special reference to serum HDL. Circulation $1979 ; 60: 1220-29$.

47. Kiens B, Jorgensen I, Lewis S, Jensen G, Lithe 11 H, Vessby B, Hoe $S$, Schnohr P. Increased plasma HDL-cholesterol and apo AI in sedentary middle-aged men after physical conditioning. Europ $\mathrm{J}$ Clin Invest 1980;16: 203-9.

48. Hartung GH, Squires WG, Gotto AM. Effect of exercise training on plasma high-density lipoprotein cholesterol in coronary heart disease patients. Am Heart J 1981;101: 181-84:

49. Hjermann I, Holme I, Velve Byre K, Leren P. Effect of diet and smoking intervention on the incidence of coronary heart disease. Lancet 1981;2:1303-13.

50. Ernst N, Fisher M, Smith $W$, Gordon T, Rifkind BM, Mishkel JA, Williams OD. The association of plasma high-density lipoprotein cholesterol with dietary intake and alcohol consumption. The lipid research clinics program prevelance study. Circulation 1980;62:41-52.

51. Hjermann I, Enger SC, Helgeland A, Home I, Leren P., Trygg $K$. The effect of dietary changes on high density lipoprotein cholesterol. The Oslo study. Am J Med $1979 ; 66: 105-9$.

52. Connor SL, Connor WE, Sexton G. Calvin L, Bacon S. The effects of age, body weight, and family relationships on plasma 1 ipoproteins and 1 ipids in men, women, and children of randomly selected families. Circulation $1982 ; 65: 1290-98$.

53. Rossner S. Lipoprotein abnormalities in obesity. In: Mancini M, Lewis B, Contaldo F, eds. Medical complications of obesity. New York: Academic Press, 1979: 89-99. 
54. Mann GV, Teel K, Hayes O, McNally A, Bruno D. Exercise in the disposition of dietary calories: regulation of serum 1 ipoprotein and cholesterol levels in human subjects. N Eng1 J Med 1955;253:350-55.

55. Wilson DE, Lees RS. Metabolic relationships among the plasma 1ipoproteins: reciprocal changes in the concentrations of very $10 \mathrm{w}$ and low density lipoproteins in man. J C1 in Invest 1972;51:1051-57.

56. Hulley SB, Cohen R, Widdowson G. Plasma high density 1ipoprotein cholesterol level: influence of risk factor intervention. J Am Med Assoc 1977;238:2269-71.

57. Avogaro P, Cazźolato G, Bettolo BG, Quinci GB. Variations of plasma lipoproteins and apolipoproteins $B$ and $A$, in obese subjects fed with hypocaloric diet. Obes Bariat Med 1979;8:158-61.

58. Mancini M, Strazzu11o P, Contaldo F, Postiglione A, Riccardi G, Perotti N, Iovine C. Effect of prolonged fasting on plasma lipoprotein composition in obese patients. In: Hessel LW, Krans HMJ, eds. Lipoprotein metabolism and endocrine regulation. Amsterdam: Elsevier/N Holland Biomedical Press. 1979:35-43.

59. Oh SY, Dupont J, Garcia PA, Brewer WD, E1-Zoheiry A, Morrison K. Lipoprotein, lipids, and protein. changes with caloric restriction and exercise. Circulation 1979;60(supp1 II):73(abstr 279).

60. Streja DA, Marliss EB, Steiner G. The effects of prolonged fasting on plasma triglyceride kinetics in man. Metabolism 1977;26:505-15.

61. Olefsky J, Reaven GM, Farquhar JW. Effects of weight reduction on obesity: studies of 1 ipid and carbohydrate metabolism in normal and hyperlipoproteinemic subjects. $\mathrm{J} \mathrm{C} 1$ in Invest $1974 ; 53: 64-76$.

62. Wilmore JH, Royce J, Girandola RN, Katch FI, Katch VL. Body composition changes with a 10 week prograin of jogging. Med Sci Sports Exerc 1970;2:113-17.

63. Fidanza F. Effects of starvation on body composition. Am J C1 in Nutr 1980;33:1562-66. 
64. Mayhew JL, Piper FC, Holmes JA. Prediction of body density, fat weight, and lean body mass in male athletes. J Sports Med 1981;21:383-89.

65. Oscai L. The role of exercise in weight control. In: Wilmore $\mathrm{jH}$, ed. Exercise and sport sciences reviews. New York: Academic Press, vol 1, 1973;103-20.

66. Boileau RA, Buskirk ER, Horstman DH, Mendez J, Nicholas WC. Body composition change's in obese and lean men during physical conditioning. Med Sci Sports 1971;3: 183-89.

67. Parozkova J. Impact of age, diet, and exercise on mans body composition. Ann NY'Acad Sci 1963;110:661-74.

68. Appenze11er 0, Atkinson R. Nutrition for physical performance. In: Sports Medicine: fitness, training, injuries.' Baltimore: Urban and Shwarzenberg 1981:5393.

69. Schwartz RS, Brunze11 JD. Increased adipose-tissue lipoprotein-1ipase activity in moderately obese men after weight reduction. Lancet 1978;11:1230-31.

70. Taskinen MR, Nikkila EA. Effects of caloric restriction on lipid metabolism in man: changes of tissue lipoprotein lipase activities and of serum lipoproteins. Atherosclerosis $1979 ; 32: 289-99$.

71. Persson B. Lipoprotein 1ipase activity of human adipose tissue in different types of hyperlipidemia. Acta Med Scand 1973;193:447-56.

72. Sauer J, Skrede S, Eriksen J, Blomhoff J. The relation between the levels of HDL cholesterol and the capacity for removal of triglycerides. Acta Med Scan 1980;208: 199-203.

73. Kekki M. Lipoprotein-1ipase action determining plasma high density lipoprotein cholesterol level in adult normolipaemics. Atherosclerosis 1980;37:143-50.

74. Krauss RM, Wood PD, Giotas C, Waterman D, Lindgren FT. Heparin-released plasma lipase activities and lipoprotein levels in distance runners. Circulation 1979; 60 (supp1 II) :73(abstr 278). 
75. Peltonen P, Marniemi J, Hietanen E, Vuori I, Ehnholn C. Changes in serum 1 ipids, 1 ipoproteins, and heparin releasable lipolytic enzymes during moderate physical training in man: A longitudinal study. Metabolism $1981 ; 30: 518-26$.

76. Borensztajn J, Rone MS, Babirak SP, McGarr JA, Oscai LB. Effect of exercise on lipoprotein lipase activity in rat heart and skeletal muscle. Am $J$ Physiol 1975; $229: 394-97$.

77. Kussi T, Nikkila EA, Saarinen P, Varjo P, Laitinen LA. Plasma high-density lipoproteins HDL-2, HDL-3, and post-heparin plasma 1 ipases in relation to parameters of physical fitness. Atherosclerosis 1982;41:209-19.

78. Persson B, Hood B, Angervall G. Effects of prolonged fast on lipoprotein 1 ipase activity eluted from human adipose tissue. Acta Med Scand 1970;188:225-29.

79. Thompson PD, unpublished data.

80. Composition of Foods. Agricultural Handbook No. 8 . United States Department of Agriculture. Agricultural Research Service. Washington, D.C., 1976.

81. Mathews DK, Fox EL. The pysiological basis of physical education and athletics. Philadelphia: W.B. Saunders Co., 1976, p. 394.

82. Pollack ML, Schmidt DH, Jackson AS. Measurement of cardio-respiratory fitness and body composition in the clinical setting. Comparitive Therapy 1980;6:12-27.

83. Sigma Chemical Co. Creatine Phosphokinase (CPK) bulletin no. 520,1979 .

84. Harper HA, Rodwe11 VW, Mayes PA. Review of physiologiçal chemistry. Los Altos: Lange Medical Publications, 1977.

85. Sigma Chemical Co. Urea Nitrogen bulletin no, 640 , 1977.

86. Interdepartmental committee on nutrition for national defense: Manuel for nutrition surveys, National Institute of Hea1th, 2nd Ed. Bethesda, 1963. 
87. Siconolfi SF, Cullinane EM, Carleton RA, Thompson PD. Assessing $\mathrm{VO}_{2}$ max in epidemiologic studies: " modification of the Astrand-Ryhming test.. Med Sci Sport Exerc 1982; $14: 335-38$.

88. Holloszy JO. Biochemical adaptions to exercise: aerobic metabolism. In: Wilmore JH; ed. Exercise and sports review 1973;1:45-71.

89. Orloff J, Berliner RW, eds. Handbook of Physiology: Renal Physiology. Washington DC: American Physiological Society', 1965 .

90. Tietz NW. Fundamentals of Clinical Chemistry. Philadelphia: W.B. Saunders Co., 1970.

91. Frandek S, Reitman S, Sonnenwirth AC., eds. Gradwohl's clinical laboratory methods and diagnosis. St. Louis: C.V. Mosby Co., vol 1, 1970.

92. Schmidt-Nie1son B. Urea excretion in mammals. Physiol Rev $1958 ; 38: 139-68$.

93. Haralambie G, Berg A. Serum urea and amino nitrogen changes with exercise duration. Europ J App1 Physiol $1976 ; 36: 39-48$.

94. Usik SV. Changes of the urea content in the blood and organs after muscular activity. Pysiol Abstrs 1976;38: 62 (abstr 291).

95. Refsum HE, Stromme SB. Urea and creatinine in urine during and after prolonged heavy exercise. Physiol Abstrs 1974;33:247-54 (abstr 1847).

96. Magazanik A, Shapiro Y, Meytes D, Meytes I. Enzyme blood levels and water balance during a marathon race. J App1 Physio1 1974;36:214-17.

97. Dohm GL, Hecker AL, Brown WE, K1ain GJ, Puente FR, Askew EW, Beecher GR. Adaption of protein metabolism to endurance training: increased amino acid oxidation in response to training. Biochem $\mathrm{J}$ 1977;164:705-8.

98. Karpovich PV, Sinning WE. Physiology of Muscular Activity. Philadelphia: W.B. Saunders Co., 1971. 
99. Miller. AT, Blyth CS. Estimation of lean body mass and body fat from basal oxygen consumption and creatinine excretion. J App1 Physiol 1952;5:73-78.

100. Griffiths FD. Serum levels of ATP: Creatine phosphotransferase (creatine kinase). The normal range and effect of muscular activity. C1in Chim Acta 1966;13: 413-20.

101. Komi PV, Rusko H, Vos J, Vikko V. Anaerobic performance capacity in athletes. Acta Physiol Scand 1977; $100: 107-14$.

102. Renold AE, Cahill GF, eds. Handbook of Physiology: Adipose Tissue. Washington,DC: American Physiological Society, 1965.

103. Mole PA, Johnson RE. Disclosure by dietary modification of an exercise-induced protein catabolism in man. J App1 Physio1 1971;31:185-90.

104. Nelson RA, Hayles AB, Wahner HW, Molnar GD. Exercise and urinary nitrogen excretion. Fed Proc 1973;32:435 (abstr 1200).

105. Strauzenberg SE, Schneider F, Donath R, Zerbes H, Kohler E. The problem of dieting in training and athletic performance. In: Somogyi JC, Zurich R, Wijn JK, eds. Nutritional aspects of physical performance. Basel: S. Karger, 1976:133-42.

106. Henderson LO, LaGarde BS, Herbert PN. Artifactual reduction of high-density lipoprotein cholesterol estimates after dextran. sulfate-Mg percipitation. Am J C1in Path 1980;73:664-68.

107. Worthington Diagnostics. Worthington cholesterol reagent set bulletin. Millipore Corp., 1978 .

108. Henderson LO, Herbert PN, Fredericksọn DS, Heinen RJ, Easterling JC. Abnormal concentration and anomalous distribution of Apolipoprotein A-I in Tangier Disease. Metabolism 1978;27:165-174. 


\section{TABLE 1}

INITIAL PHYSICAL CHARACTERISTICS OF SIXTEEN RUNNERS

\begin{tabular}{lcc}
\hline PHYSICAL CHARACTERISTIC & MEAN \\
AGE (yrs) & 30.2 & \pm 6.6 \\
HEIGHT (inches) & 69.2 & \pm 2.4 \\
WEIGHT (lbs.) & 153.2 & $\pm 16: 1$ \\
BODY FAT (q) & 8.9 & \pm 3.0.
\end{tabular}


TABLE 2

MEAN NUTRIENT INTAKE OF SIXTEEN. RUNNERS DURING THE BASELINE AND HYPOCALORIC PERIODS NUTRIENTS

\section{BASELINE}

NUTRIENTS
HYPOCALORIC

\section{DIFFERENCE}

PERCENT

DIFFERENCE

\begin{tabular}{lrrrrrrr}
\hline & MEAN & \multicolumn{1}{c}{ SD } & MEAN & SD & MEAN & SD & PERCENT \\
\hline Energy (kcal) & 3757.0 & 409.0 & 2821.0 & 451.0 & 936.0 & 42.0 & -25.2 \\
Carbohydrate (gm) & 501.3 & 52.2 & 390.6 & 57.1 & 110.7 & 4.9 & -22.4 \\
Protein (gm) & 142.9 & 15.3 & 111.0 & 17.2 & 31.9 & 1.9 & -22.6 \\
Nitrogen (gm) & 893.0 & 95.9 & 699.4 & 98.5 & 193.6 & 2.6 & -21.7 \\
Fat (gm) & 135.6 & 17.6 & 98.6 & 18.3 & 37.0 & 0.7 & -27.8 \\
SFA (gm) & 51.5 & 7.6 & 35.8 & 7.4 & 15.7 & 0.2 & -31.0 \\
PFA (gm) & 27.5 & 4.1 & 18.9 & 4.2 & 8.6 & 0.1 & -31.9 \\
Cholesterol (mg) & 522.8 & 47.0 & 426.2 & 45.3 & 96.6 & 1.7 & -18.5 \\
P:S ratio & 0.53 & 0.0 & 0.53 & 0.0 & 0.0 & -0.0 & 0.0
\end{tabular}


TABLE 3

MEAN AND SD VALUES FOR BODY WEIGHT, LEAN BODY WEIGHT, AND PERCENT BODY FAT OF 16 . RUNNERS (DAYS 1,8 , and 18)

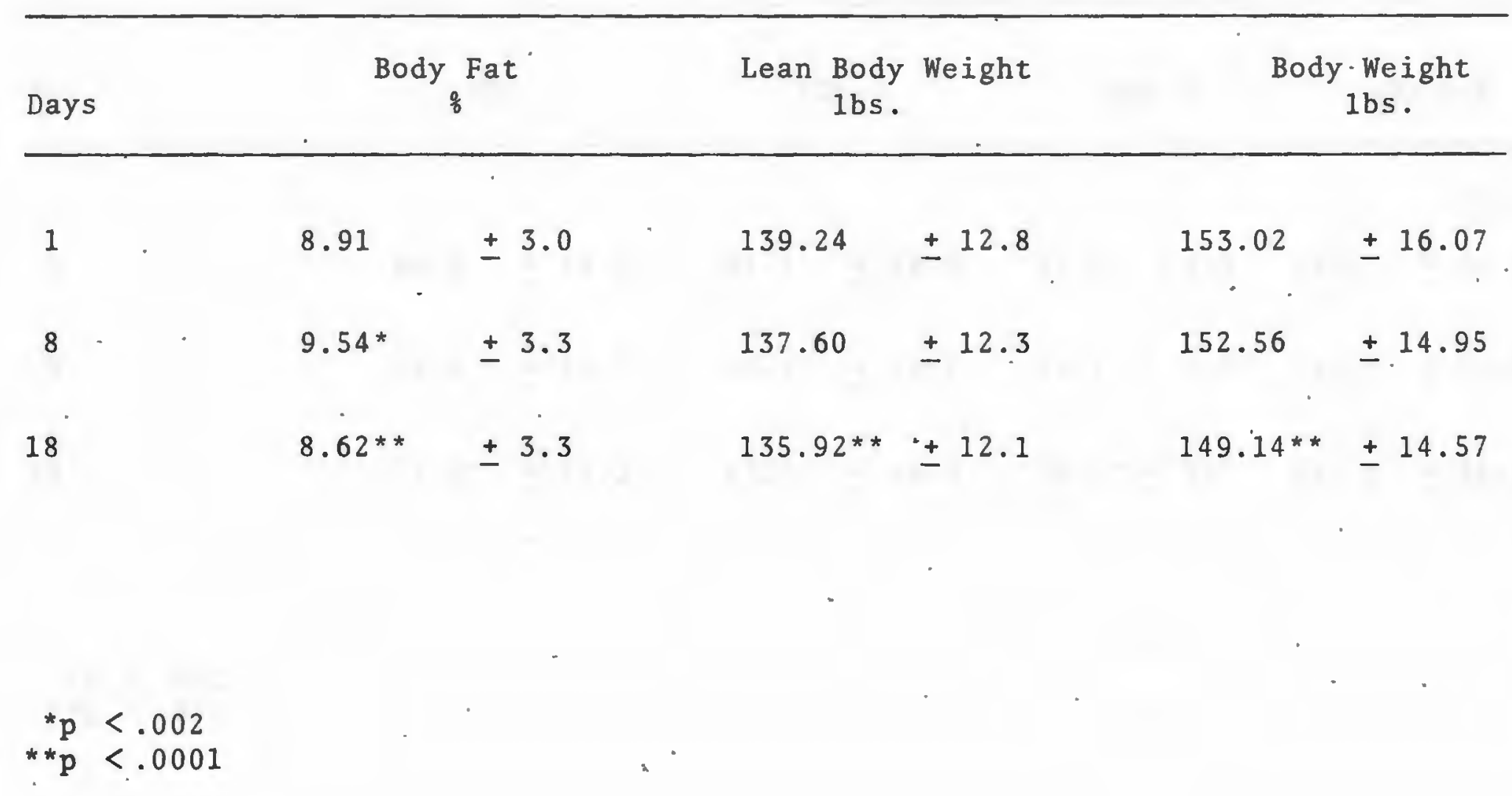


TABLE 4

MEAN. SERUM AND SD VALUES FOR HDL AND APO A-I LEVELS

OF SIXTEEN RUNNERS (DAYS 1,8 , and 18)

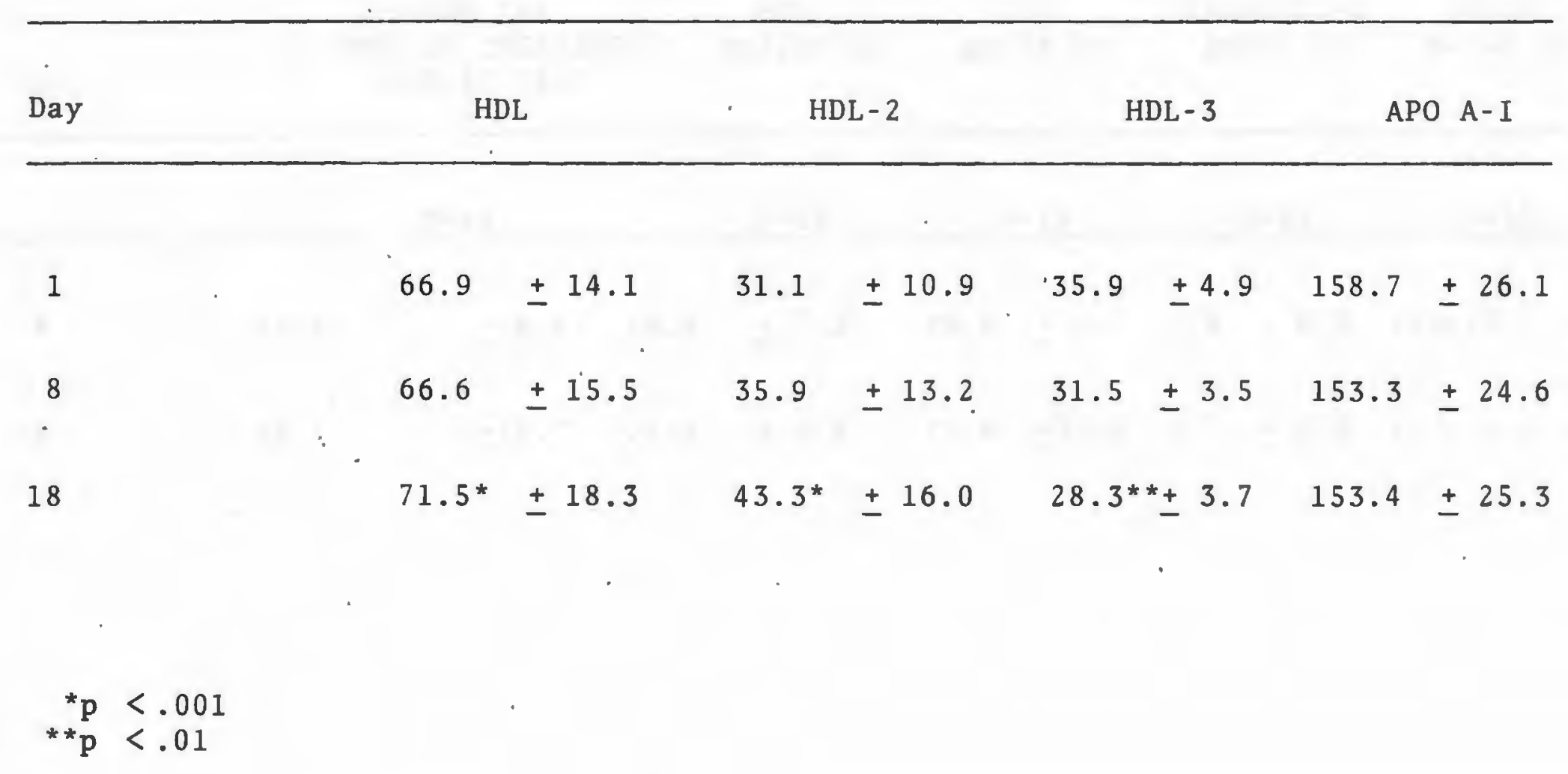


TABLE 5

MEAN AND SD VALUES FOR CPK AND MUSCLE METABOLITES

DURING THE HYPOCALORIC PERIOD (DAYS 8 and 18)

\begin{tabular}{|c|c|c|c|c|c|}
\hline DA.YS & $\begin{array}{c}\text { SERUM CPK } \\
1 \text { NMOL OF CREATINE/ } \\
\text { MIN AT } 25^{\circ} \mathrm{C}\end{array}$ & $\begin{array}{c}\text { BUN } \\
\mathrm{mg} / 100 \mathrm{~m} 1\end{array}$ & $\mathrm{gm} / 24 \mathrm{hr}$ & $\begin{array}{l}\text { - CREAT ININE } \\
\mathrm{gm} / 24 \mathrm{hr}\end{array}$ & $\begin{array}{l}\text { URINE } \\
\text { VOLUME } \\
\text { m1/24 hr }\end{array}$ \\
\hline
\end{tabular}

$N=16$

$\mathrm{N}=16$

$\mathrm{N}=15$

$\mathrm{N}=15$

$\mathrm{N}=15$

$\stackrel{\infty}{0}$

8

18
16.5

26.7

$$
\pm 6.4
$$

28.8

$\pm 7.2$

26.0

$\pm 9.1$

2.9 $+10.7$ $\pm 5.6$
$21.8 \pm 10.6$

2.7 
FIGURE 1

PLOT OF MEAN CHANGE IN CALORIES OVER 18 DAY PERIOD

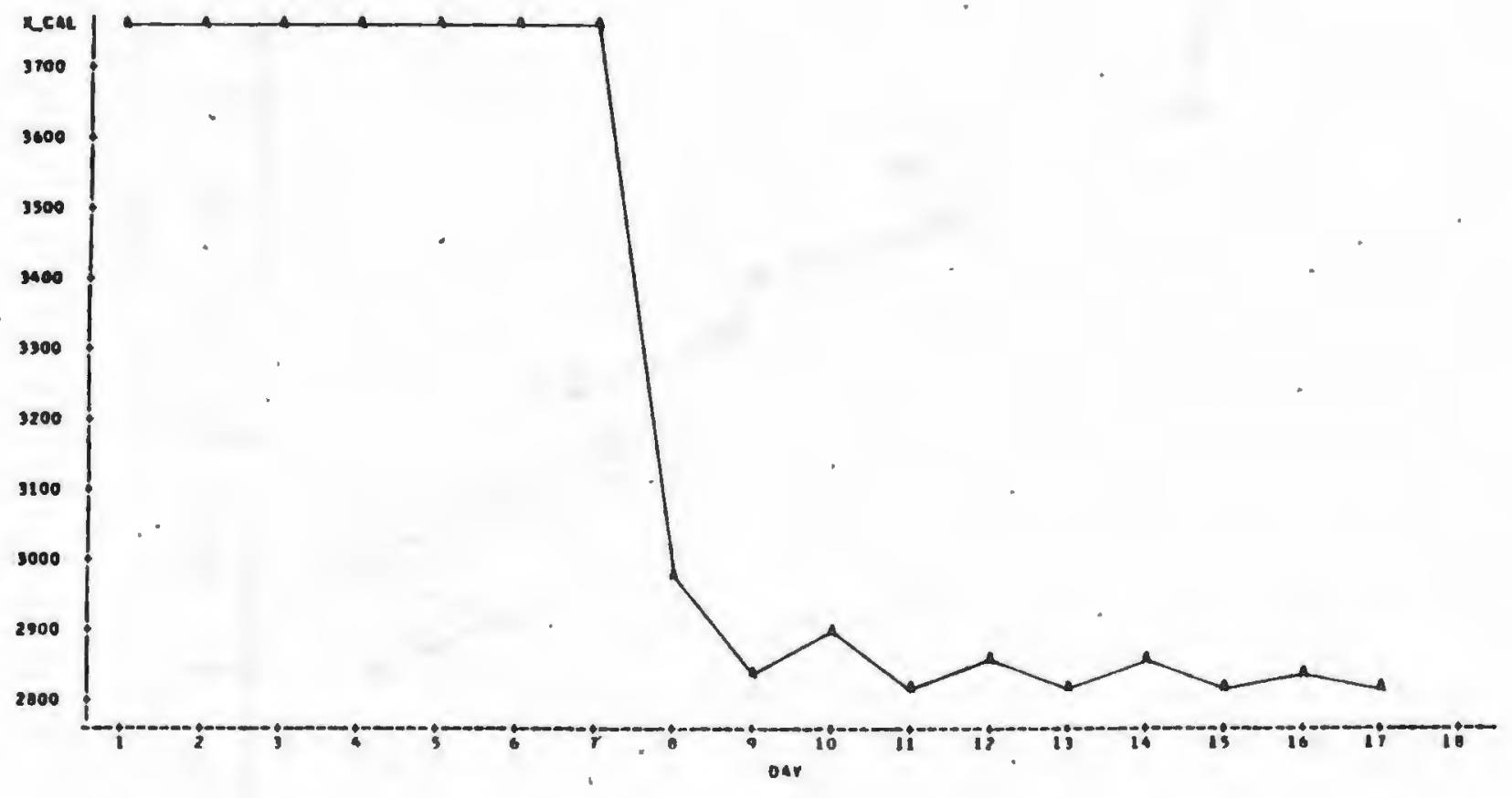


FIGURE 2

MEAN CHANGE IN WEIGHT BY DAY

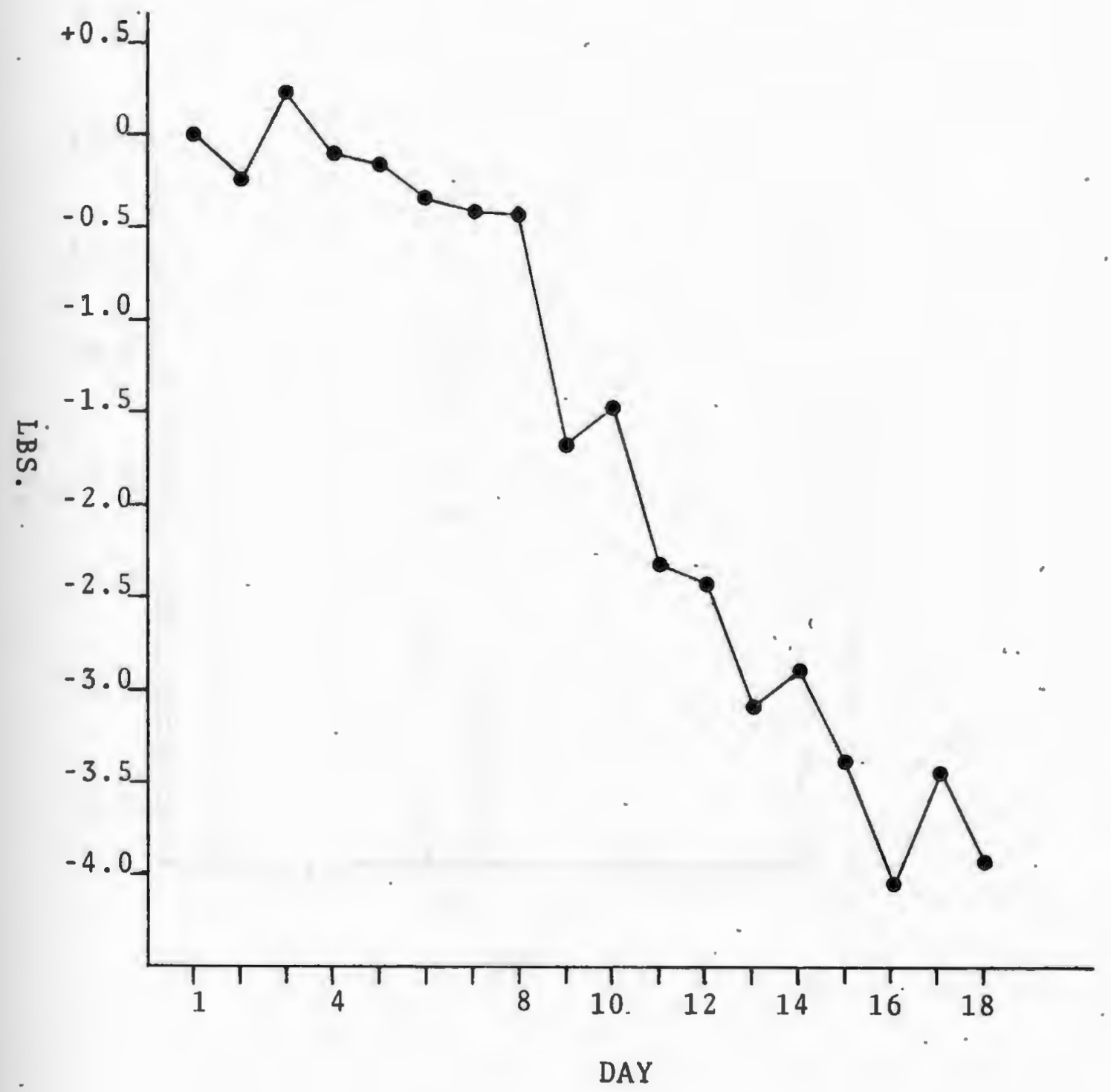


FIGURE 3

MEAN CHANGES IN PERCENT FAT BY DAY

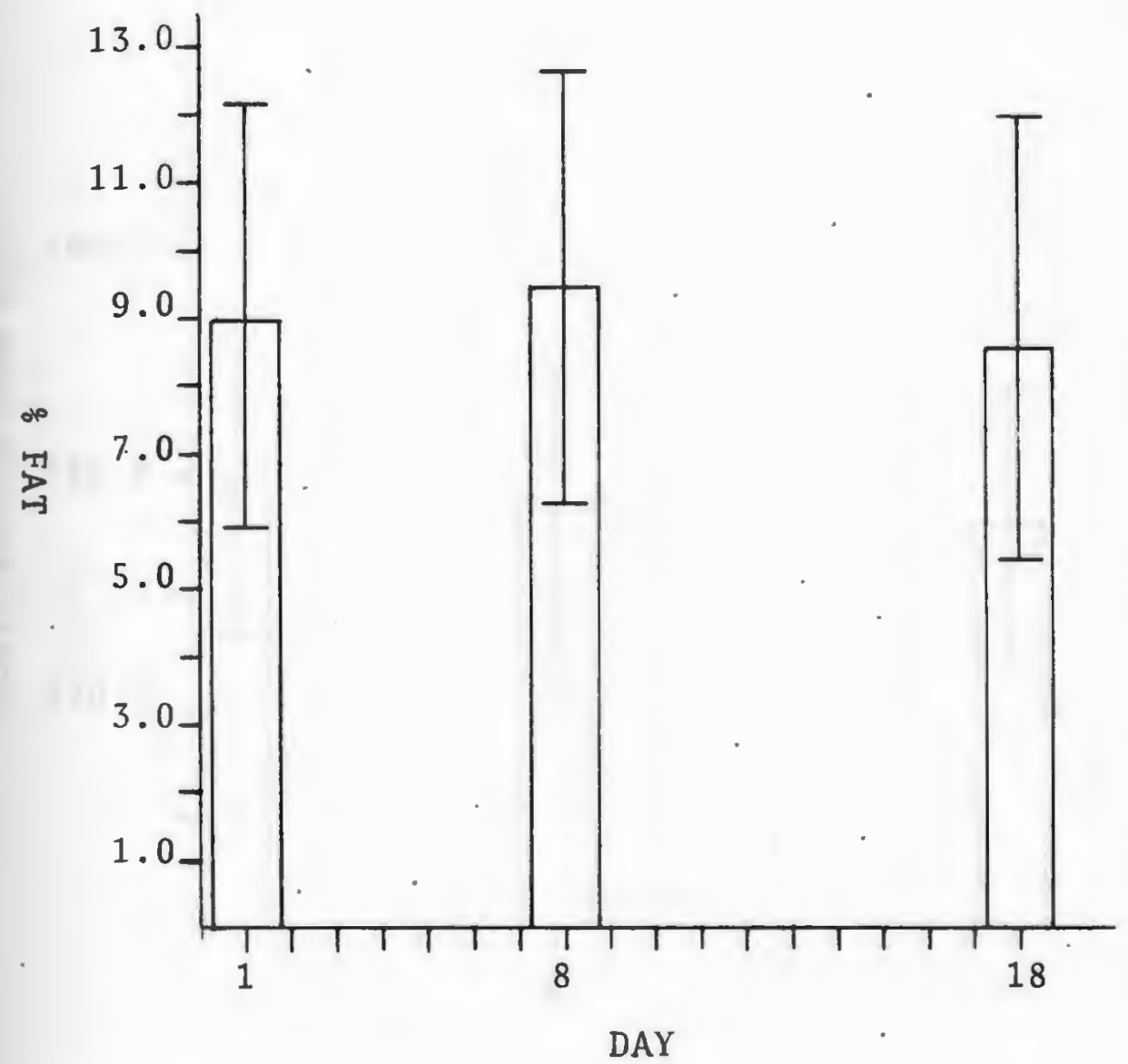


FIGURE 4

MEAN CHANGES IN LEAN BODY WEIGHT BY DAY

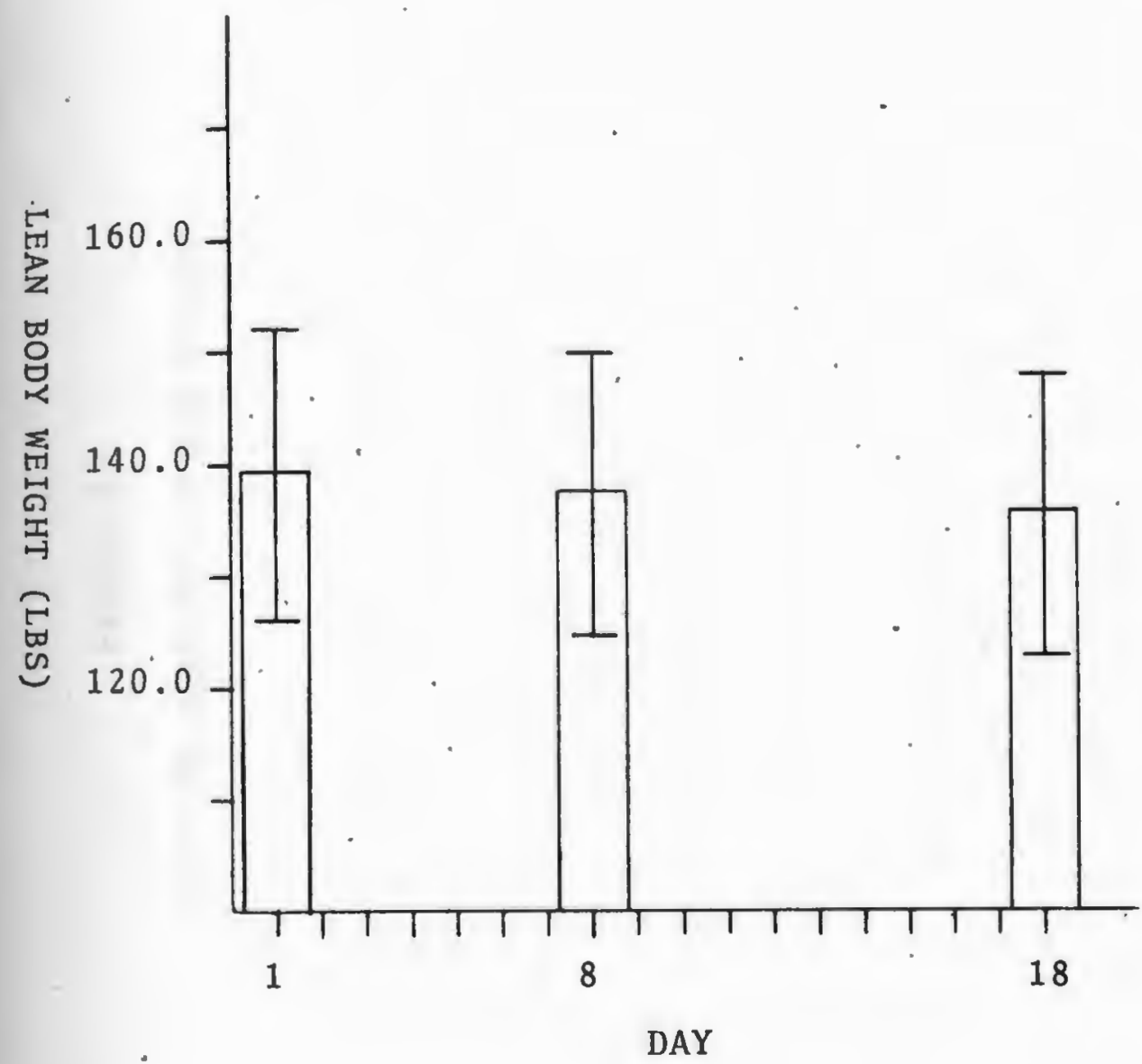




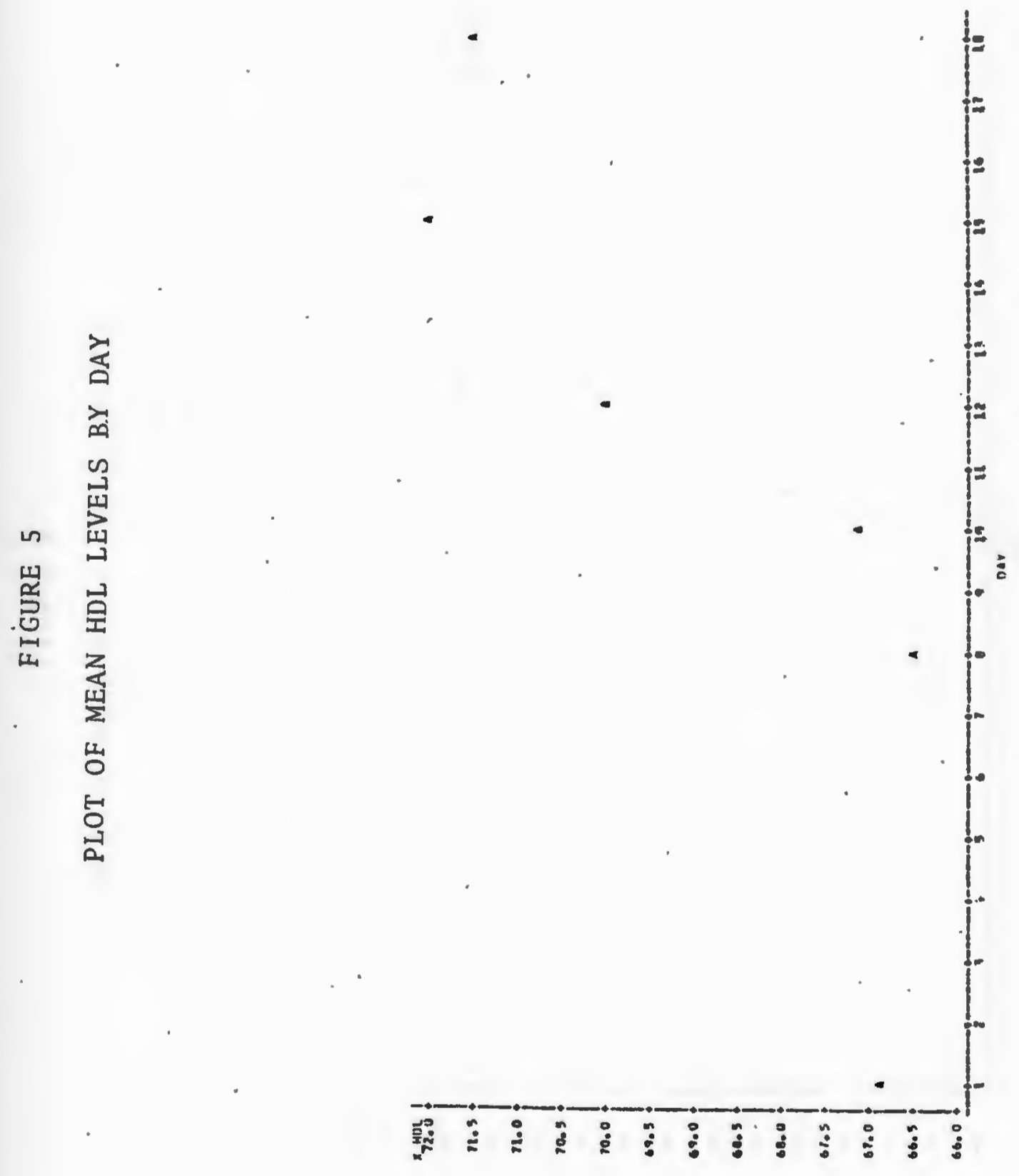



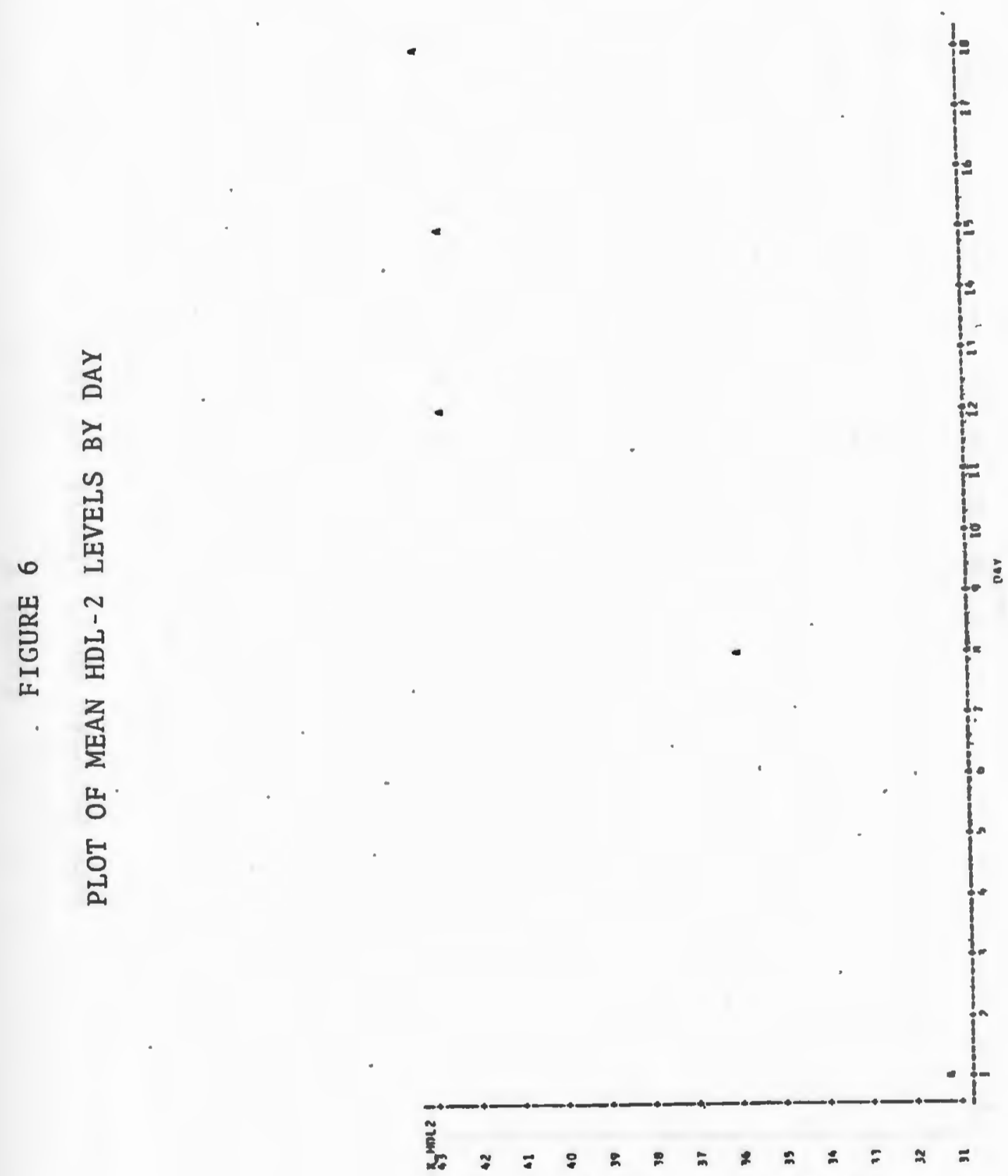


$$
\begin{aligned}
& \text { 容 } \\
& \sim \text { 焉 } \\
& \text { 崖 } \\
& \text { 茍葟 } \\
& \text { 丞 } \\
& \text { 동 } \\
& \text { 号 }
\end{aligned}
$$

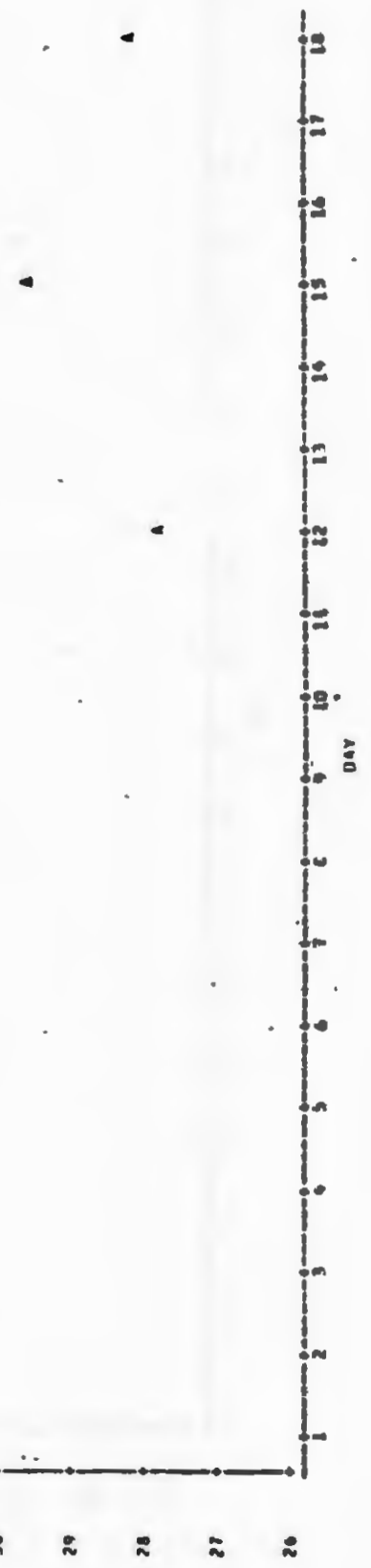


FIGURE· 8

PLOT OF MEAN APO A-I LEVELS BY DAY

$\infty$

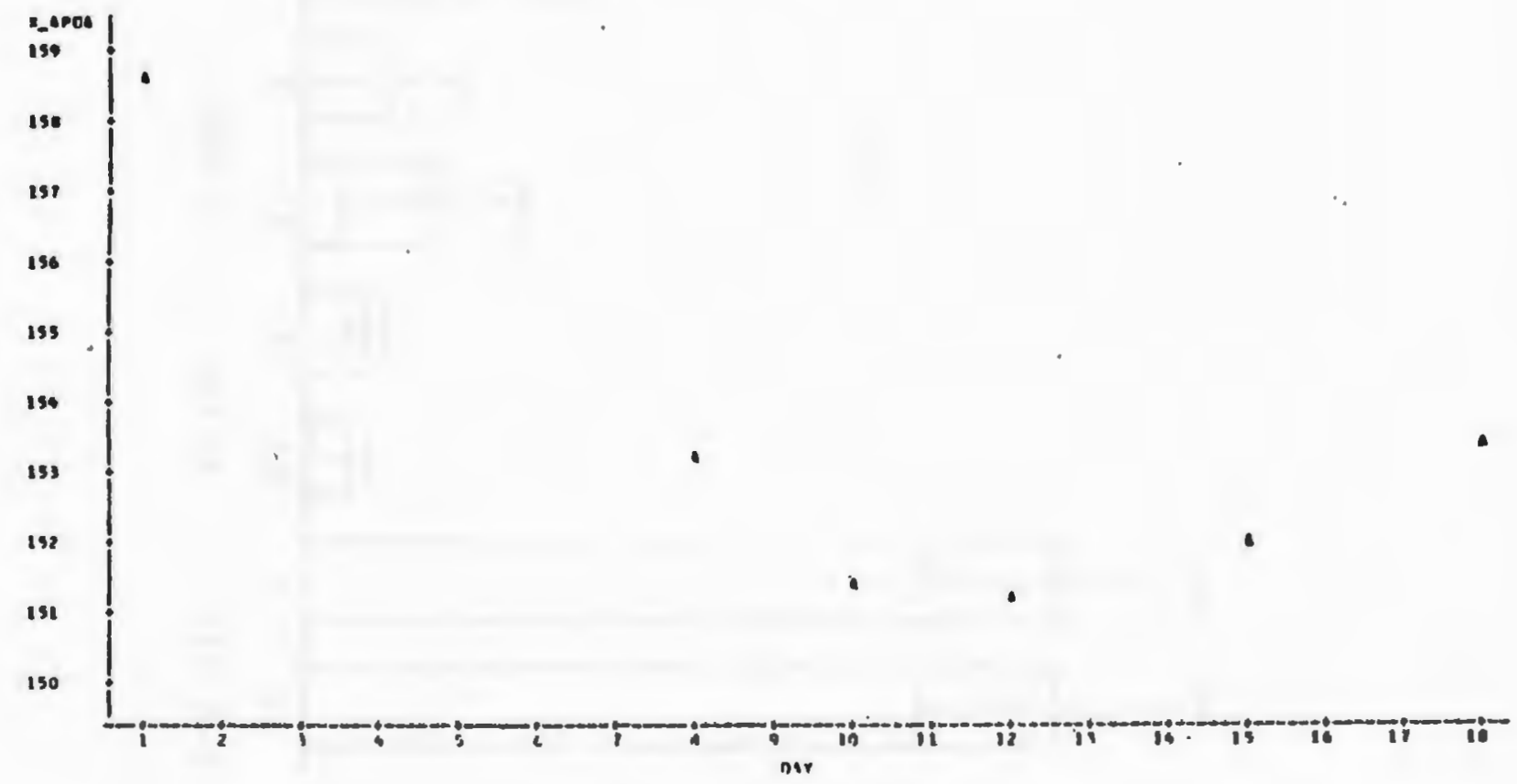


FIGURE 9

MEAN HDL AND APO A-I LEVELS DURING THE HYPOCALORIC PERIOD

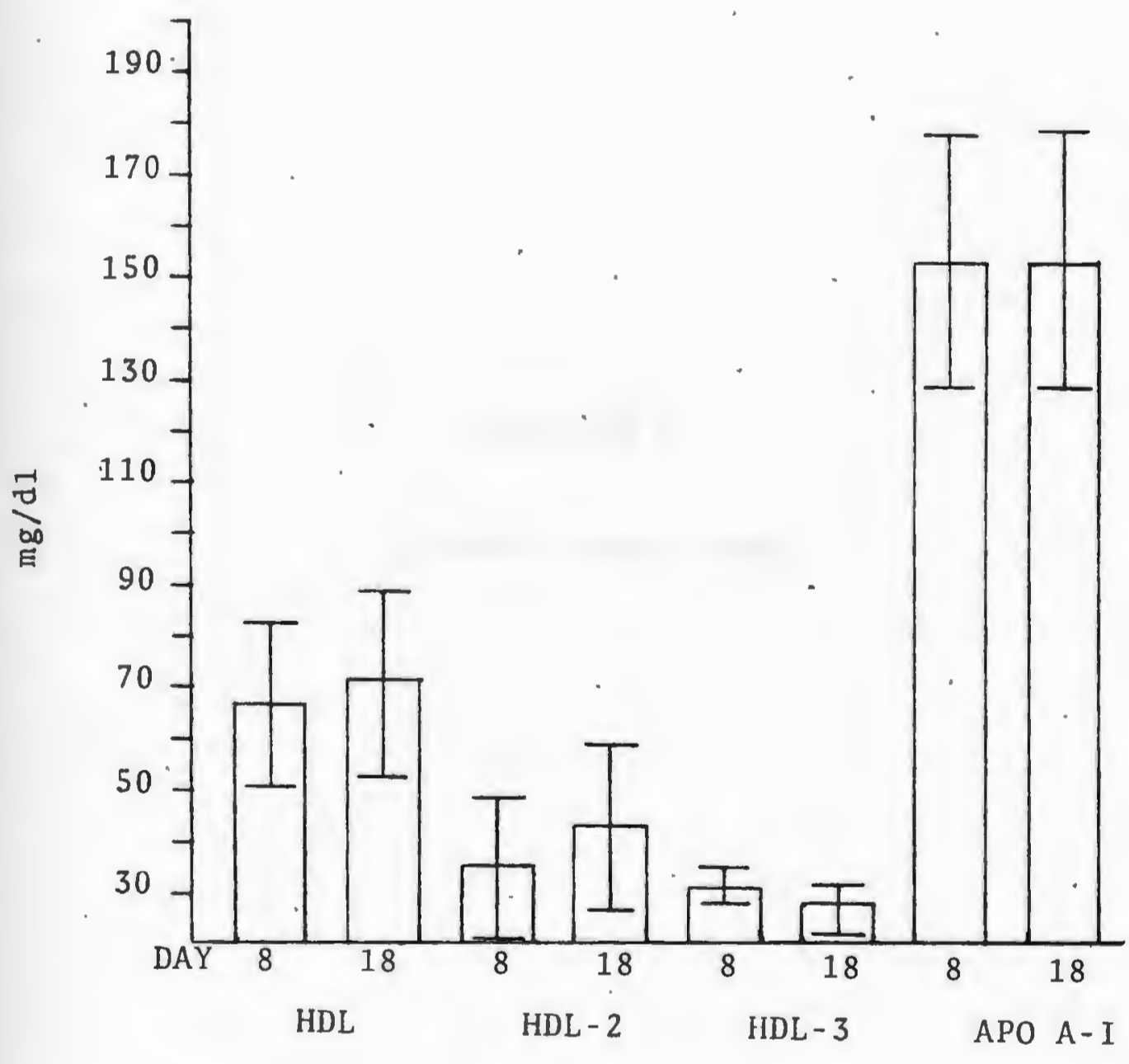


APPENDIX 1

24 HOUR RECALL FORM 


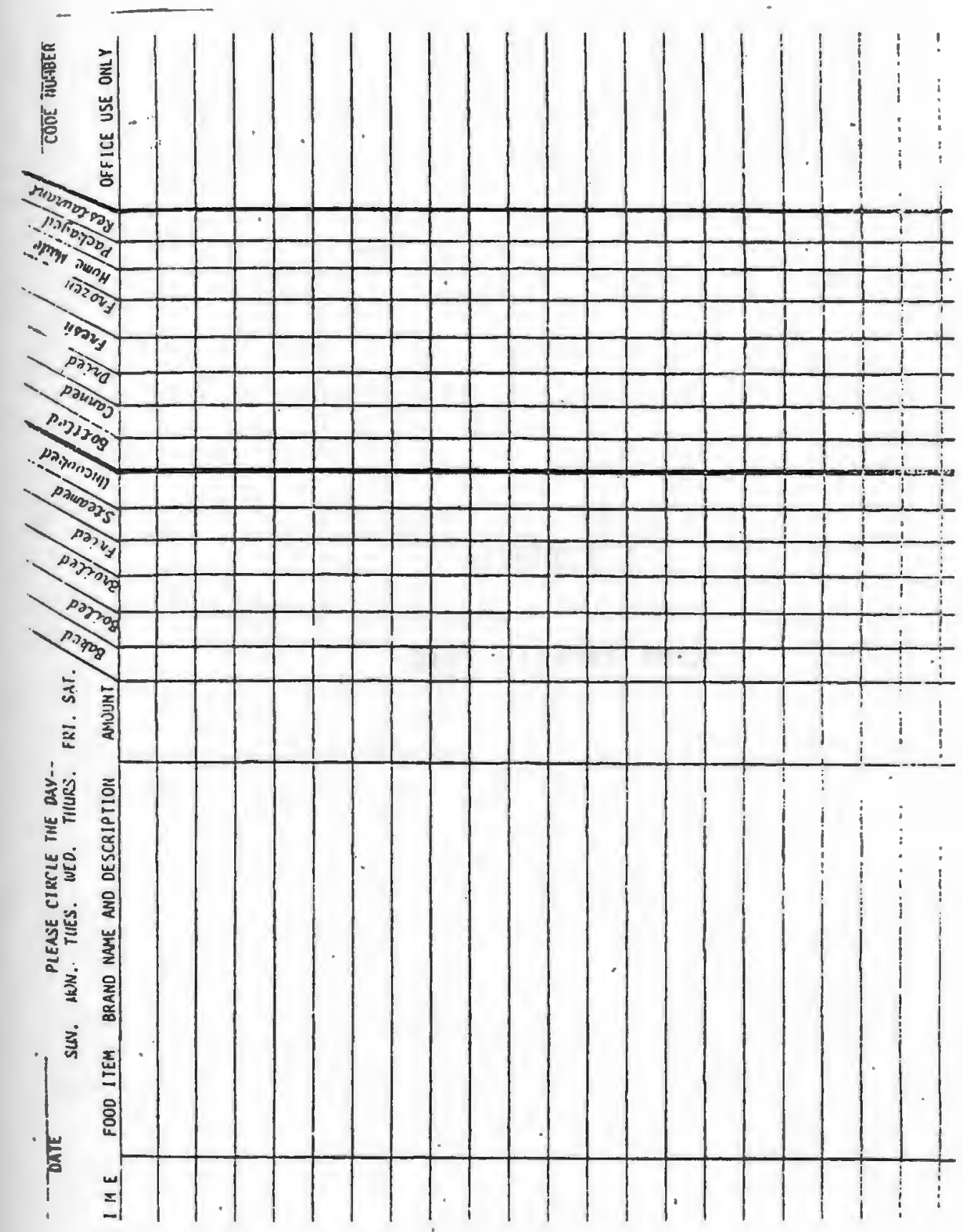


APPENDIX 2

DIET HISTORY FORM 
1. Subject's Name

Number

2. Name of Spouse, Wife, or Friend

3. Date

4. Impression of Interview:

5. License \#

6. Meal Hours: M-F B $\mathrm{L}^{\circ}$ D

$$
\text { Sat/Sun B }
$$

L D

7. Phone \#: Work Home

8. Tell me about your job.

9. Interviewer's Signature

10. Does your wife work?

Hours

Hypocaloric Dietary Interview with $\quad \begin{array}{ll}\text { Name } \\ \text { Date }\end{array}$ Participant

Introduction: Statement of purpose of dietary interview. Interview: How do you describe your appetite?

Excellent

Good

Fair

Poor

How many people are there in your family at home: Adults Children 
Sa1t:

Do you add salt to your food before you

taste it? yes

Do you salt your food after you

taste it?

yes

Do you never add salt to

food?

$$
\text { yes }
$$

no

no

no

Diet:

Have you ever been on a diet? yes

When?

no

How Long?

Kind

How well did you tolerate this diet?

Was it prescribed by a Doctor?

yes no

How soon before or after you run, do you eat?

How long have you been running?

What changes have there been in your food habits since you began to run?

Weight

Appetite

Food and eating

Do you take vitamin or mineral supplements?

$$
\text { yes }
$$

Frequency

no

Do you take other food supplements? yes Kind

Have you experienced any changes in bowel habits, diarrhea, etc.? (since running)

Do you use laxatives or stool softners?

Frequency of bowe1 habits

Do you experience gastric distress (gas)?

Beverages

Coffee 
Cups/day?

Regular

Decaffinated

Sugar

Tea

Cups/day?

Regular

Herbal

Sugar

- Do you drink anything else?

Frequency

Do you drink any alcoholic beverages?

Do you like apple juice?

orange juice?

How much milk do you drink per day or use in coffee, cereal, etc?

Kind

How often do you use cream?

Do you like whole grain bread?

How often do you use it?

How often do you eat cereal?

Kind

Do you ever eat other whole grain products?

Kind

Do you like chicken? Frequency eaten

Do you like a cold chicken salad or plate for dinner, or do you prefer a hot meal at night?

Do you like whițe rice? Frequency eaten

Do you like rice pudding? 
Do you like egg noddles? Frequency eaten

Did you ever eat noddle pudding?

What kinds of vegetables do you like (fresh, canned, frozen)?

Do you like fresh salad (vegetable)?

What types of fresh vegetables do you like in salad?

What is your usual portion size of salad?

Sma11

Average

Large

Second Helpings

Do you like frozen cooked green beans?

Frequency eaten

Do you 1ike: (Raw)

Frequency

Celery

Radishes

Red Cabbage

Cucumbers

Spinach

Mushrooms

Lettuce (Kind)

Green Pepper

(Talk about great salad dressings)

Do you like milkshakes?

Kind

How often do you have dessert, and if you do, what do you consider dessert?

What kinds of fruit do you usually eat? (fresh, canned, frozen)

Do you like bananas? Frequency eaten

Do you like canned yellow peaches in heavy syrup? Frequency eaten

Do you like raisins?

Frequency eaten

Do you like peanuts? Frequency eaten

Do you like applesauce?___ Frequency eaten

Would you be willing to collect your urine twice for 24 hours? 


\section{APPENDIX 3}

COMPOSITION OF BASELINE DIET 


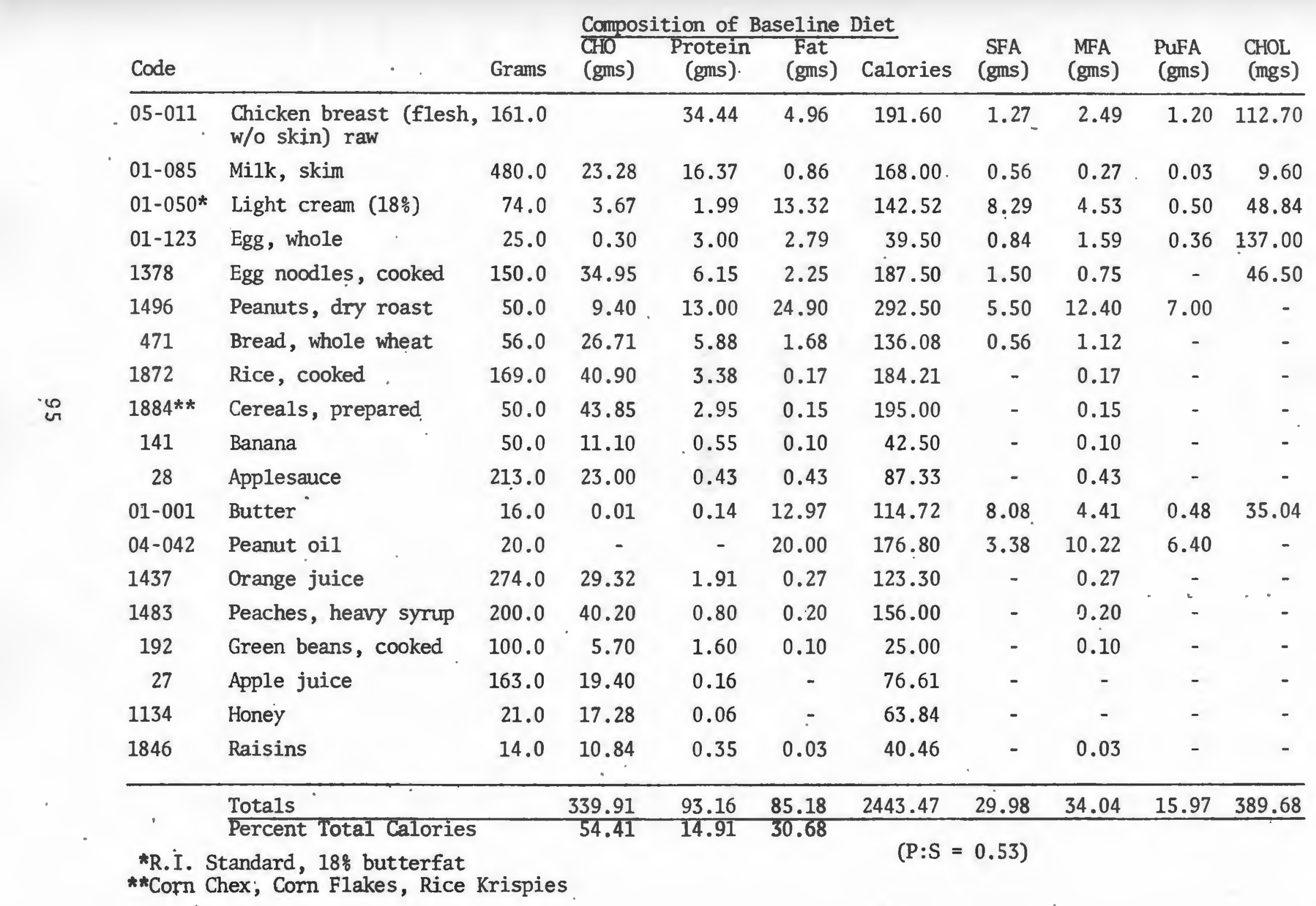


APPENDIX 4

SAMPLE MENU 


\section{MENU PLAN}

\section{BREAKFAST}

(gms)

50 Banana (raw)

74 Light Cream (cereal, coffee)

240 Skim Milk (cereal)

274 Orange Juice (frozen)

50 Cerea 1
LUNCH

(gms)

81 Chicken

54 Bread

6 Butter

\begin{tabular}{|c|c|}
\hline & $\begin{array}{l}\text { Celery/Green } \\
\text { Peppers }\end{array}$ \\
\hline 213 & Applesauce \\
\hline 163 & Apple Juice \\
\hline SNACK & $\begin{array}{l}\text { (consumed any } \\
\text { time) }\end{array}$ \\
\hline (gms) & \\
\hline 50 & Peanuts \\
\hline & $\begin{array}{r}\text { Peaches (heavy } \\
\text { syrup) }\end{array}$ \\
\hline 120 & Skim Milk \\
\hline 14 & Raisins \\
\hline
\end{tabular}

Peppers

213 Applesauce

163 Apple Juice

SNACK (consumed any time)

(gms)

DINNER

(gms)

80 Chicken

$150 \mathrm{Egg}$ Noodles

100 Green Beans (frozen, steamed)

20 Peanut $0 i 1$

120 Skim Milk

169 Rice

21 Honey

10 Butter

$25 \mathrm{Egg} \mathrm{(salad} \mathrm{or} \mathrm{cooking)}$

Mixed Salad

Coffee/Tea (iced or hot) 
APPENDIX 5

SAMPLE RECIPES 


\section{PEACHY CHICKEN}

$80 \mathrm{gm}$ chicken

sa1t

pepper

$24 \mathrm{gm}$ peach juice

$36 \mathrm{gm}$ peaches

$14 \mathrm{gm}$ raisins $\frac{1}{4}$ c. chicken broth

$\frac{1}{2} t$. white vinegar

$\frac{1}{4} t$. onion flakes

$\frac{1}{4}$ t. 1 emon juice

sprinkle tumeric

Sprinkle chicken with salt and pepper. Brown in a pan sprayed with pam. Combine peach juice with other ingredients. Add to chicken. Simmer 10 minutes. Add peaches. Heat gently (approx. 2 minutes). Serve over the noddles or rice.

\section{RICE PUDDING WITH BANANAS}

$169 \mathrm{gm}$ cooked rice

$120 \mathrm{gm} \mathrm{skim} \mathrm{milk}$

$25 \mathrm{gm} \mathrm{egg}$
50 gm chopped banana

$21 \mathrm{gm}$ honey

$10 \mathrm{gm}$ butter

Spray pyrex bowl with pam. Melt butter in pyrex over double boiler. Add rice, egg, banana, and honey. Crush $12.5 \mathrm{gm}$ cornfalkes from breakfast cereal for topping. Bake in 375 $F$ oven for 40 minutes. 
APPENDIX 6

COMPOSITION OF THE MUFFIN 


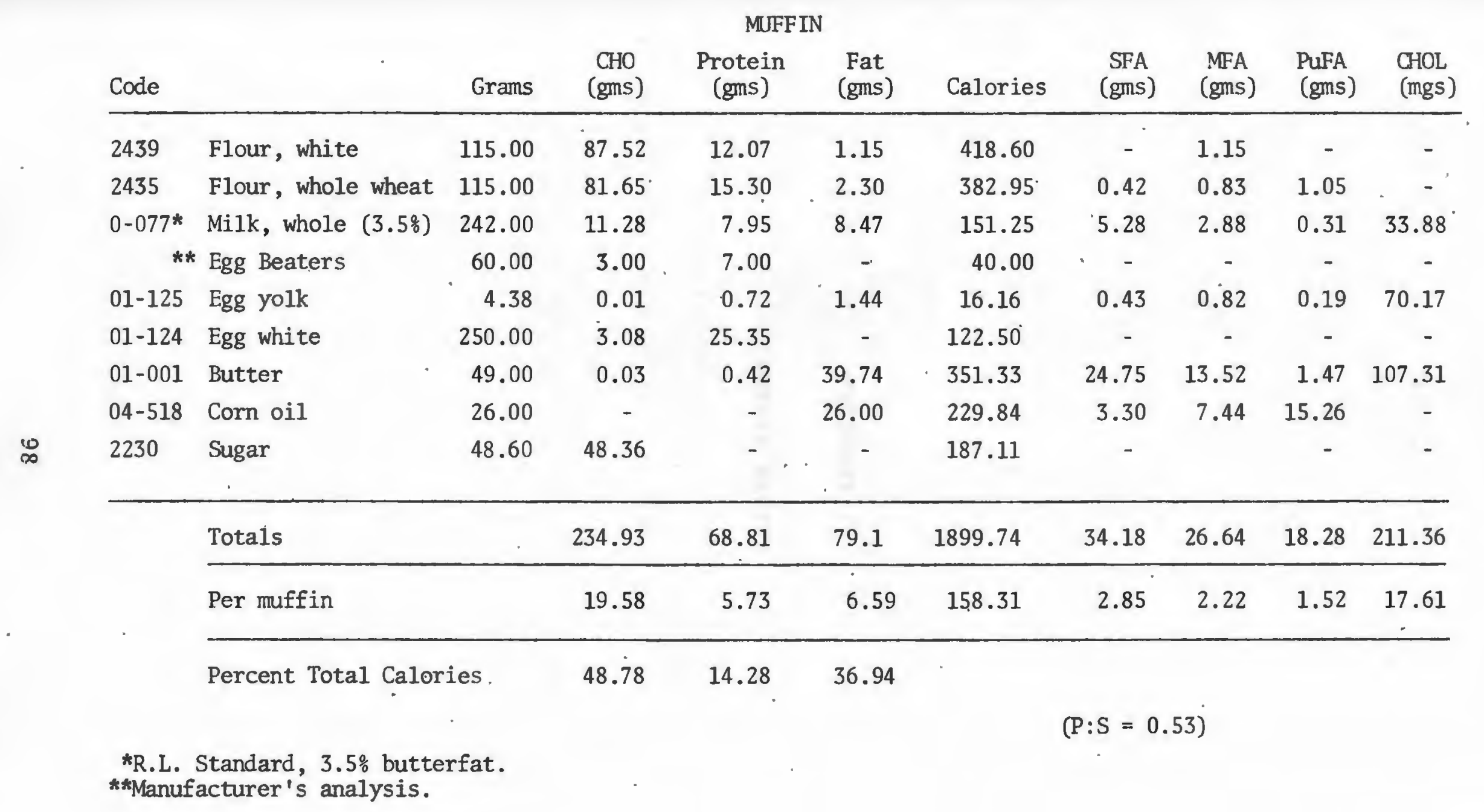


APPENDIX 7

MUFFIN RECIPE 


\section{MUFF IN}

Weigh:

$\begin{array}{cl}.115 \mathrm{~g} & \text { Enriched white flour } \\ 115 \mathrm{~g} & \text { Whole wheat flour } \\ 48.6 \mathrm{~g} & \text { Sugar } \\ 1.0 \mathrm{~g} & \text { Salt } \\ 11 \mathrm{~g} & \text { Baking powder }\end{array}$

Mix dry ingredients

Weigh:

$\begin{array}{ll}60 \mathrm{~g} & \text { Eggbeaters } \\ 4.38 \mathrm{~g} & \text { Egg yolk } \\ 49 \mathrm{~g} & \text { Butter--melted in a bow1 over hot water } \\ 26 \mathrm{~g} & \text { Corn oil. } \\ 242 \mathrm{~g} & \text { Whole milk } \\ 250 \mathrm{~g} & \text { Egg whites }\end{array}$

Weigh and mix dry ingredients.

Combine butter, oil, eggbeaters, yolk, and milk. Add to dry ingredients (scraping bow1) and mix--about 25 strokes.

Beat egg whites until frothy and fold in--just until mixed. Pam muffin tins. Bake for 30 minutes at $425^{\circ}$. 


\section{APPENDIX 8}

COMPOSITION OF THE SALAD 
SALAD COMPOSITION

\begin{tabular}{|c|c|c|c|c|}
\hline 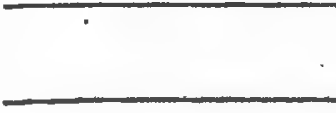 & Calories & $\begin{array}{c}\mathrm{CHO} \\
\text { (gm). }\end{array}$ & $\begin{array}{l}\text { Protein } \\
\text { (gm) }\end{array}$ & $\begin{array}{l}\text { Fat } \\
\text { (gm) }\end{array}$ \\
\hline Radish ( $1 \mathrm{c}$ ) & 7.0 & 1.0 & 0.3 & 0.03 \\
\hline Mushroom $\left(\frac{1}{2} \mathrm{c}\right)$ & 10.0 & 1.5 & 1.0 & 0.1 \\
\hline $\begin{array}{l}\text { Spinach/ } \\
\text { Lettuce (1c) }\end{array}$ & 14.0 & 2.4 & 1.8 & 0.2 \\
\hline Cucumber $\left(\frac{1}{2} c\right)$ & 8.0 & 1.8 & 0.4 & 0.04 \\
\hline
\end{tabular}


APPENDIX 9

METHODS OF ANALYSES FOR HDL AND APO A-I 
The following analyses were performed at the Nutrition and Metabolism Research Laboratory at Miriam Hospital, Providence, Rhode Island:

I. Analysis of HDL

Determining the HDL-cholesterol in the HDL fraction of serum or plasma has been widely adopted as a convenient method for estimating HDL concentrations. The method determines HDL-cholestero1, HDL-2, and HDL- 3 by a modification of the Lipid Research Clinic, in which 1:0 $\mathrm{ml}$ samples for heparin-MnC1 percipitation were used (106). The Worthington Cholesterol Reagent set was used to determine HDLcholestero1 (107). HDL-2 and HDL-3 were separated after VLDL and LDL were percipitated with the heparin-MnC1 reagent (106).

\section{Analysis of APO A-I}

APO A-I was measured by radioimmunoassay which was a double-antibody procedure (108). 


\section{B IBLIOGRAPHY}

Appenzeller 0, Atkinson R. Nutrition for physical performance. In: Sports Medicine: fitness, training, injuries. Baltimore: Urban and Shwarzenberg 1981:53-93.

Avogaro P, Cazzolato G, Bettolo BG, Quinci GB. Variations of plasma lipoproteins and apolipoproteins $B$ and $A$, in obese subjects fed with hypocaloric diet. Obes Bariat Med $1979 ; 8: 158-61$.

Ball KP. Is diet an essential risk factor for coronary heart disease? Post Grad Med.1980;56:585-92.

Barr DP, Russ EM, Eder HA. Protein-lipid relationships in human plasma II. In: Atherosclerosis and related conditions. Am J Med 1951;11:480-93.

Berg A, Keul J, Ringwald G, Deus B, Wybitul K. Physical performance and serum cholesterol fractions in healthy young men. C1in Chim Acta 1980;106:325-30.

Boileau RA, Buskirk ER, Horstman DH, Mendez J, Nocholas WC. Body composition changes in obese and lean men during physical conditioning. Med Sci Sports 1971;3:183-89.

Borensztajn J, Rone MS, Babirak SP, McGarr JA, Oscai LB. Effect of exercise on lipoprotein lipase activity in rat heart and skeletal muscle. Am J Physiol 1975;229:394-97.

Buskirk ER, Thompson RH, Lutwak L, Whedon GD. Energy balance of obese patients during weight reduction: influence of diet and exercise. Ann NY Acad Sci 1963;110:91840 .

Carew TE, Koschinsky T, Hayes SB, Steinberg D. A mechanism by which high density lipoproteins may slow the atherogenic process. Lancet 1976;2:1315-17.

Composition of Foods. Agricultural Handbook No. 8. United States Department of Agriculture. Agricultural Research Service. Washington, D.C., 1976.

Connor SL, Connor WE, Sexton G, Calvin L, Bacon S. The effects of age, body weight, and family relationships on plasma lipoproteins and lipids in men, women and children of randomly selected families. Circulation 1982;65:1290-98. 
Contaldo F, Strazzu110 P, Postiglione A, Riccardi G, Patti L, Di Biase G, Mancini M. Plasma high density lipoprotein in severe obesity after stable weight 1oss. Atherosclerosis $1980 ; 37: 163-67$.

Dohm GL, Hecker AL, Brown WE, Klaịn GJ, Puente FR, Askew EW, Beecher GR. Adaption of protein metabolism to endurance training: increased amino acid oxidation in response to training. Biochem $\mathrm{J}$ 1977;164:705-8.

Ernst N, Fisher M, Smith W, Gordon T, Rifkind BM, Mishke1 JA, Williams OD. The association of plasma high-density 1ipoprotein cholesterol with dietary intake and alcohol consumption. The lipid research clinics program prevelance study. Circulation $1980 ; 62: 41-52$.

Fidanza F. Effects of starvation on body composition. Am $J$ C1 in Nutr $1980 ; 33: 1562-66$.

Frandek S, Reitman S, Sonnenwirth AC., eds. Gradwohl's clinical laboratory methods and diagnosis. St Louis: C.V. Mosby Co., vol 1, 1970.

G1omset JA. Physiological role of lecithin: cholesterol acyl-transferase. Am J C1 in Nutr 1970;23:1129-36.

Goldstein JL, Brown MS. The low-density lipoprotein pathway and its relation to atherosclerosis. Ann Rev Biochem $1977 ; 46: 897-930$.

Gordon T, Castelli W, Hjortland MG, Kannel WB, Dawber TR. High density lipoprotein as a protective factor against coronary heart disease. The Framingham study. Am J Med $1977 ; 62: 704-14$.

Griffiths FD. Serum levels of ATP: Creatine phosphotransferase (creatine kinase). The normal range and effect of muscular activity. Clin Chim Acta 1966;13:413-20.

Haralambie G, Berg A. Serum urea and amino nitrogen changes with exercise duration. Europ J App1 Physiol 1976; $36: 39-48$.

Harper HA, Rodwe11 VW, Mayes PA. Review of physiological chemistry. Los Altos: Lange Medical Publications, 1977.

Hartung, GH, Foreyt JP, Mitchel1 RE, V1asek J, Gotto AM. 
Relation of diet to high-density-1ipoprotein cholesterol. in middle-aged marathon runners, joggers, and inactive men. N Eng1. J Med 1980;302:357-61.

Hartung GH, Squires WG, Gotto AM. Effect of exercise training on plasma high-density lipoprotein cholesterol in coronary heart disease patients. Am Heart J 1981;101: $181-84$.

Henderson LO, Herbert PN, Fredrickson DS, Heinen RJ, Easterling JC. Abnormal concentration and anomalous distribution of Apolipoprotein A-I in Tangier Disease. Metabolism 1978; $27: 165-174$.

Henderson LO, LaGarde BS, Herbert PN. Artifactual reduction of high-density lipoprotein cholesterol estimates after dextran sulfate-Mg percipitation. Am $\mathrm{J}$ Clin Path $1980 ; 73: 664-68$.

Hjermann I, Holme I, Velve Byre K, Leren P. Effect of diet and smoking intervention on the incidence of coronary heart disease. Lancet 1981;2:1303-13.

Hjermann I, Enger SC, Helgeland A, Holme I, Leren P, Trygg $K$. The effect of dietary changes on high density lipoprotein cholesterol. The Oslo study. Am J Med 1979;66:105-9.

Holloszy Jo. Biochemical adaptions to exercise: aerobic metabolism. In: Wilmore $\mathrm{JH}$, ed. Exercise and sports reviews $1973 ; 1: 45-71$.

Hulley SB, Cohen R, Widdows on G. Plasma high density lipoprotein cholesterol level: influence of risk factor intervention. J Am Med Assoc 1977;238:2269-71.

Huttunen JK, Ehnholm C, Kekki M, Nikkila EA. Post-heparin plasma lipoprotein lipase and hepatic lipase in normal subjects and in patients with hypertriglyceridemia: corre1ations to sex, age, and various parameters of triglyceride metabolism. C1in Sci Mol Med 1976;50:249-60.

Huttunen JK, Lansimies E, Voutilainen E, Penttila I, Sutonen 0 , Rauramaa $R$. Effect of moderate physical exercise on serum lipoproteins. A controlled clinical trial with special reference to serum HDL. Circulation 1979;60:122029. 
Interdepartmental committee on nutrition for national defense: Manuel for nutrition surveys, National Institute of Health, 2nd Ed. Bethesda, 1963.

Jackson RL, Morrisett JD, Gotto AM. Lipoprotein structure and metabolism. Physiol Rev 1976;56:259-301.

Kannel WB, Caste11i WP, Gordon T. Cholesterol in prediction of atherosclerotic disease. Ann Intern Med 1979;90:85-91.

Karpovich PV, Sinning WE. Physiology of Muscular Activity. Philadelphia: W.B. Saunders (C)., 1971.

Kekki M. Lipoprotein-lipase action determining plasma high density 1 ipoprotein cholesterol level in adult normolipaemics. Atherosclerosis 1980;37:143-50.

Keys A. Alpha lipoprotein (HDL), cholesterol in the serum and risk of coronary heart disease and death. Lancet 1980; $1: 603-6$.

Keys A, Anderson JT, Grande F. Serum cholesterol response to changes in the diet II. The effect of cholesterol in the diet. Metabolism 1965;14:759-64.

Kiens B, Jorgensen I, Lewis S, Jensen G, Lithe 11 H, Vessby B, Hoe, Schnohr P. Increased plasma HDL-cholesterol and apo $A I$ in sedentary middle-aged men after physical conditioning. Europ J C1in Invest 1980;16:203-9.

Komi PV, Rusko H, Vos J, Vikko V. Anaerobic performance. capacity in athletes. Acta Physiol Scand 1977;100:107-14.

Krauss RM, Wood PD, Giotas C, Waterman D, Lindgren FT. Heparin-released plasma lipase activities and lipoprotein levels in distance runners. Circulation 1979;60(supp1 II): 73 (abstr 278).

Kussi T, Nikkila EA, Saarinen P, Varjo P, Laitinen LA. Plasma high-density 1 ipoproteins HDL-2, HDL-3, and postheparin plasma lipases in relation to parameters of physical fitness. Atherosclerosis 1982;41:209-19.

Lehtonen A, Viikari J. Serum triglycerides and cholester01 and serum high-density lipoprotein cholesterol in highly physically active men.' Acta Med Scand 1978;204:111-i4. 
Leon AS, Conrad J, Hunninghake DB, Serfass R. Effects of a vigorous walking program on body composition and carbohydrate and lipid metabolism of obese young men. Am $\mathrm{J}$ C1in Nutr 1979;32:1776-87.

Levy RI. Cholesterol, 1ipoproteins, apoproteins, and heart disease: present status and future prospects. C1in Chem $1981 ; 27: 653-62$.

Lewis S, Haske11.WL, Wood PD, Manoogian N, Bailey JE, Pereia MB. Effects of physical activity on weight reduction in obese middle-aged women. Am J C1in Nutr 1976;29: $151-56$.

Magazanik A, Shapiro Y, Meytes D, Meytes I. Enzyme blood levels and water balance during a marathon race. J Appl Physio1 1974;36:214-17.

Mancini M, Strazzullo P, Contaldo F, Postiglione A, Riccardi G, Perotti N, Iovine C. Effect of prolonged fasting on plasma lipoprotein composition in obese patients. In: Hessel LW, Krans HMJ, eds. Lipoprotein metabolism and endocrine regulation. Amsterdam: Elsevier/N Holland Biomedica1 Press, 1979:35-43.

Mann GV, Teel K, Hayes 0, McNally A, Bruno D. Exercise in the disposition of dietary calories: regulation of serum lipoprotein and cholesterol levels in human subjects. N Eng1 J Med 1955;253:350-55.

Masarei JRL, Pyke JE, Pyke FS. Physical fitness and plasma HDL cholesterol concentrations in male business executives. Atherosclerosis $1982 ; 42: 77-83$.

Mathews DK, Fox EL. The pysiological basis of physical education and athletics. Philadelphia: W.B. Saunders Co., 1976 , p. 394.

Mayhew JL, Piper FC, Holmes. JA. Prediction of body density, fat weight, and lean body mass in male athletes. J Sports Med 1981;21:383-89.

Miller AT, Blyth CS. Estimation of lean body mass and body fat from basal oxygen consumption and creatinine excretion. J Appl Physiol 1952;5:73-78.

Miller GJ, Miller NE. Plasma high density lipoprotein con- 
centration and development of ischaemic heart disẹse. Lancet 1975;1:16-19.

Mole PA, Johnson RE. Disclosure by dietary modification of an exercise-induced protein catabolism in man. J Appl Physiol 1971;31:185-90.

Nicol1 E, Miller NE, Lewis B. High density lipoprotein metabolism. Adv Lipid Res 1980;17:53-106..

Nikkila EA, Taskinen MR, Rehunen S, Harkensen M.' Lipoprotein lipase activity in adipose tissue and skeletal muscle of runners: relation to serum lipoproteins. Metabolism $1978 ; 27: 1661-71$.

Nikkila EA, Taskinen MR, Kekki M. Relation of plasma highdensity 1 ipoprotein cholesterol to 1 ipoprotein 1 ipase activity in adipose tissue and skeletal muscle of man. Atherosclerosis $1978 ; 29: 497-501$.

Nelson RA, Hayles AB, Wahner HW, Molnar GD. Exercise and urinary nitrogen excretion. Fed Proc 1973;32:435 (abstr 1200).

Oh SY, Dupont J, Garcia.PA, Brewer WD, E1-Zoheiry A, Morri-. son K. Lipoprotein, 1ipids, and protein changes with caloric restriction and exercise. Circulation 1979;60 (supp1 II): 73 (abstr 279).

Olefsky J, Reaven GM, Farquhar JW. Effects of weight reduction on obesity: studies of lipid and carbohydrate metabolism in normal and hyperlipoproteinemic subjects. J C1in Invest $1974 ; 53: 64-76$.

Orloff J, Berliner RW, eds. Handbook of Physiology: Renal Physiology. Washington DC: American Physiological Society, 1965 .

Oscai L. The role of exercise in weight control. In: Wilmore JH, ed. Exercise and sport sciences reviews. New York: Academic Press, vol 1, 1973:103-20.

Parozkova J. Impact of age, diet, and exercise on mans body composition. Ann NY Acad Sci 1963;110:661-74.

Patsch JR; Gotto AM, Olivecrona T, Eisenberg S. Formation of high density lipoprotein-2 like particles during lipoly- 
sis of very low density lipoproteins in vitro. Proc Nat1 Acad Sci 1978;75:4519-23.

Peltonen P, Marniemi J, Hietanen E, Vuori I, Ehnholm'C. Changes in serum 1 ipids, 1 ipoproteins, and heparin releasable lipolytic enzymes during moderate physical training in man: A longitudina1 study. Metabolism 1981;30:518-26.

Persson B. Lipoprotein lipase activity of human adipose tissue in different types of hyperlipidemia. Acta Med Scand $1973 ; 193: 447=56$.

Persson B, Hood B, Angerval1 G. Effects of prolonged fast on lipoprotein 1 ipase activity eluted from human adipose tissue. Acta Med Scand 1970;188:225-29.

Pollack ML, Schmidt DH, Jackson AS. Measurement of cardiorespiratory fitness and body composition in the clinical setting. Comparitive Therapy 1980;6:12-27.

Refsum HE, Stromme SB. Urea and creatinine in urine during and after prolonged heavy exercise. Physiol Abstrs 1974; 33:247-54 (abstr 1847).

Renold AE, Cahill GF, eds. Handbook of Physiology: Adipose Tissue. Washington DC: American Physilogical Society, 1965 .

Ross R, Glomset A. The pathogenesis of atherosclerosis I. N Eng1 J Med 1976;295:369-75.

Ross R, Glomset JA. The pathogenesis of atherosclerosis II. N Eng1 J Med 1976;295:420-25.

Rossner S. Lipoprotein abnormalities in obesity. In: Mancini $M$, Lewis $B$, Contaldo F, eds. Medical complications of obesity. New York: Academic Press, 1979:89-99.

Sauer J, Skrede S, Eriksen J, Blomhoff J. The relation between the levels of HDL cholesterol and the capacity for removal of triglycerides. Acta Med Scan 1980;208:199-203.

Schaefer EJ, Foster DM, Jenkins LL, Lindgren FT, Berman M, Levy $R$, Brewer HD. The composition and metabolism of high density 1ipoprotein subfractions. Lipids 1979;14:511-21.

Schmidt-Nielson B. Urea excretion in mammals. Physiol Rev 
Schonfield G, Weidman SW, Witztum JL, Bowen RM. Alterations in levels and interrelations of plasma apopolipoproteins induced by diet. Metabolism 1976;25:261-75.

Schwartz RS, Brunzel1 JD. Increased adipose-tissue 1ipoprotein-lipase activity in moderately obese men after weight reduction. Lancet 1978;11:1230-31.

Schwartz RS, Brunzell JD. Increase of adipose tissue 1ipoprotein lipase activity with weight loss. J Clin Invest $1981 ; 67: 1425-30$.

Shekelle RB, Shyrock AM, Oglesky P, Lepper M, Stamler J, Lui S, Raynor WJ. Diet, serum cholesterol, and death from coronary heart disease. The Western Electric study. N Eng1 J Med 1981;304:65-70.

Siconolfi SF, Cullinane EM, Carleton RA, Thompson PD. Assessing $\mathrm{VO}_{2}$ max in epidemiologic studies: modification of the Astrand-Ryhming test. Med Sci Sport Exerc 1982;14:33538 .

Sigma Chemcial Co. Creatine Phosphokinase (CPK) bulletin no. 520,1979 .

Sigma Chemical Co. Urea Nitrogen bulletin no. 640, 1977.

Smith LC, Pownal1 HJ, Gotto AM. The plasma lipoproteins: structure and metabolism. Ann Rev Biochem 1978;47:751-77.

Smith MP, Mendez J, Druckenmiller M, Kris-Etherton PM. Exercise intensity, dietary intake, and high density lipoprotein cholesterol in young female competitive swimmers. Am J C1 in Nutr 1982;36:251-55.

Strauzenberg SE, Schneider F, Donath R, Zerbes H, Kohler E: The problem of dieting in training and athletic performance. In: Somogyi JC, Zurich R, Wijn JK, eds. Nutritional aspects of physical performance. Rase1: S. Karger, 1976: $133-42$.

Streja DA, Marliss EB, Steiner G. The effects of prolonged fasting on plasma triglyceride kinetics in man. Metabolism $1977 ; 26: 505-15$. 
Ta11 AR, Sma11 DM. Plasma high density lipoproteins. N Eng1 J Med 1978;299:1232-36.

Tan MH, Sata T, Havel RJ. The significance of lipoprotein lipase in rat skeletal muscles. J Lipid Res 1977;18:363-70.

Taskinen MR, Nikkila EA. Effects of caloric restriction on lipid metabolism in man: changes of tissue lipoprotein lipase activities and of serum lipoproteins. Atherosclerosis $1979 ; 32: 289-99$.

Taskinen MR, Nikkila EA. High density lipoprotein subfrac-, tions in relation to lipoprotein lipase activity of tissues in man - evidence for reciprocal regulation of HDL-2 and HDL-3 levels by lipoprotein lipase. Clin Chim Acta 1981; $112: 325-31$.

Thompson PD, unpublished data.

Thompson PD, Eshleman RE, Cullinane E, Herbert PN. Effects of varying caloric or carbohydrate intake on the serum 1 ipids and 1 ipoprotein concentrations of endurance athletes, unpublished.

Thompson PD, Jeffery RW, Wing.RR, Wood PD. Unexpected decrease in plasma high density 1 ipoprotein cholesterol with weight 1oss. Am J C1in Nutr 1979;32:2016-21.

Tietz NW. Fundamentals of Clinical Chemistry. Philadelphia: W. B. Saunders Co., 1970.

Usik SV. Changes of the urea content in the blood and organs after muscular activity. Pysiol Abstrs 1976;38:62 (abstr 291).

Vodak P, Wood P, Haskell W, Williams P. HDL-cholesterol and other plasma lipid and lipoprotein concentrations in middleaged male and female tennis players. Metabolism.1980;29: $745-52$.

Weltman A, Matter S, Stanford B. Caloric restriction and/or mild exercise: effects on serum lipids and body composition. Am J C1 in Nutr 1980;33:1002-9.

Wetzler HP. Exercise, diet, and high-density lipoprotein cholesterol. N Engl J Med 1980;303:223-24. 
Williams PT, Wood PD, Haskell WL, Vranizan K. The elfects of running mileage and duration on plasma lipoprotein levels. J Am Med Assoc 1982;247:2674-79.

Wilmore JH, Royce J, Girandola RN, Katch FI, Katch VL. Body composition changes with a 10 week program of jogging. Med Sci Sports Exerc 1970;2:113-17.

Wilson DE, Lees RS. Metabolic relationships among the plasma 1 ipoproteins: reciprocal changes in the concentrations of very low and low density 1 ipoproteins in man. $\mathrm{J}$ Clin Invest 1972;51:1051-57.

Wolansky H. A proposal linking clearance of circulating lipoproteins to tissue metabolic activity as a basis for understanding atherogenesis. Circulation Res 1980;47:301-9.

Wood PD, Haskell WL. The effect of exercise on plasma high density 1ipoproteins. Lipids 1979;14:417-27.

Wood PD, Haskell W, Klein H, Lewis S, Stern MP, Farquhar JW. The distribution of plasma lipoproteins in middle-aged male runners. Metabolism 1976;25:1249-57.

Worthington Diagnostics. Worthington cholesterol reagent set bulletin. Millipore Corp., 1978.

Young L, Barboriak JJ. Exercise, diet, and high density1ipoprotein cholesterol. N Engl J Med 1980;303:223-24. 